Supporting Information

\title{
Bio-based Non-Isocyanate Polyurethanes as Recyclable and Intrinsic Self-Healing Coating with Triple Healing Sites
}

\author{
Ping Sen Choong, ${ }^{\mathrm{a}}$ Ning X Chong, ${ }^{\mathrm{a}}$ Eric Kwok Wai Tam, ${ }^{\mathrm{a}}$ Abdul Majeed Seayad, ${ }^{\mathrm{b}}$ Jayasree Seayad, ${ }^{a *}$ \\ and Satyasankar Jana ${ }^{\text {a* }}$
}

aFunctional Molecules \& Polymers, Institute of Chemical and Engineering Sciences, Agency for Science, Technology and Research ( $A^{*}$ STAR), 1 Pesek Rd, Singapore, 627833.

${ }^{b}$ Process and Catalysis Research, Institute of Chemical and Engineering Sciences, Agency for Science, Technology and Research (A*STAR), 1 Pesek Rd, Singapore, 627833.

*Email: satyasankar_jana@ices.a-star.edu.sg and jayasree_seayad@ices.a-star.edu.sg 


\section{Table of Contents}

Content

Page

I. Experimental Section 3

II. General Polymerization Procedures for NIPUs 4-6

III. General Procedures for Diels-Alder crosslinking of NIPUs with Bismaleimide 6

$\begin{array}{lll}\text { IV. } & \text { Crosslink density calculation of NIPU-bismaleimide } & 7\end{array}$

V. Scheme S1 8

VI. Table S1: Details of polymerization and polymers 9

VII. Figure S1: ${ }^{1} \mathrm{H}$ NMR spectra, overlay thermogravimetric analysis plots and differential scanning calorimetry plots of all four NIPUs.

VIII. Figure S2-7: Overlay ${ }^{1} \mathrm{H}$ NMR spectra of NIPU polymerization reactions \& polymers

IX. Figure S8: DSC plots of moistened NIPUs

X. Figure S9-16: ${ }^{1} \mathrm{H}$ NMR spectra of NIPUs crosslinked with BM $18-25$

XI. Figure S17-23: Microscopic images on thermo-healing and self-healing of crosslinked NIPU coatings

XII. Figure S24: DSC plots of dry and moistened poly(FBC-DAP)-BM2

XIII. Table S2:Summary of mechanical properties of NIPU-bismaleimide coatings 34

XIV. References 


\section{Experimental Section}

\section{Materials}

All reagents and solvents were purchased from commercial sources and used without further purification. FBA was purchased from Biosynth Carbosynth (Compton, United Kingdom) and 1,1'-(methylenedi-4,1-phenylene)bismaleimide (BM1) was purchased from Sigma Aldrich. Reported procedures were used for synthesis of $\mathrm{BBC},{ }^{[1]} \mathrm{FBC},{ }^{[2]} \mathrm{SuBC},{ }^{[3]}$ and BM2.[4]

\section{Instrumentation}

${ }^{1} \mathrm{H}$ NMR spectra were recorded on a Bruker Ultra Shield Advance 400 Autosampler (400 $\mathrm{MHz}$ ) using dimethyl sulfoxide-d6 as the solvent. The chemical shifts were reported in parts per million (ppm) and the following abbreviations were used to describe the multiplicities: $\mathrm{s}=$ singlet, $\mathrm{d}=$ doublet, $\mathrm{t}=$ triplet, $\mathrm{q}=$ quartet, $\mathrm{m}=$ multiplet, $\mathrm{br}=$ broad. Size exclusion chromatography (SEC) analysis was carried out on a Waters Binary GPC system with the Waters 2414 Refractive Index Detector. Dimethylformamide (DMF) was used as the eluent with a flow rate of $0.3 \mathrm{~mL} / \mathrm{min}$ and PMMA standards were used for calibration. Elemental analysis of polymers was carried out on a Thermo Fisher Scientific FLASH 2000 CHNS/O Analyzer. Thermogravimetric analysis (TGA) spectra of polymers were recorded on a TA Instruments TGA-Q500 with heating rate of $10^{\circ} \mathrm{C} / \mathrm{min}$ under air. Differential Scanning Calorimetry (DSC) data were recorded on a Mettler Toledo DSC 3 with a heating rate of $10{ }^{\circ} \mathrm{C} / \mathrm{min}$ under nitrogen. Microscopy images were recorded on a Nikon Eclipse Ci-L microscope system. Pencil hardness (ASTM D3363) of coating was measured by a Elcometer 501 Pencil Hardness Tester with pencil grades from $6 \mathrm{~B}$ to $6 \mathrm{H}$. Pendulum hardness (ASTM D4366) of coating was measured on a BYK Pendulum Hardness Tester equipped with a König pendulum. The period of oscillation in seconds for pendulum deflection from $6^{\circ}$ to $3^{\circ}$ was recorded. Pull-off strength (ASTM D4541) of coating was tested by a Defelsko PosiTest AT with a $20 \mathrm{~mm}$ aluminum dolly. Coating thickness was measured by using an Elcometer 456 Coating Thickness Gauge on aluminum substrate. Dynamic mechanical analysis (DMA) of polymers was carried out in tensile mode on a NETZSCH dynamic mechanical analyzer DMA 242 E Artemis. 


\section{General Polymerization Procedure for NIPUs}

The general polymerization procedure of Poly(BBC-FBA), Poly(FBC-FBA), and Poly(FBC-DAP) is described as follows:. A mixture of bis(cyclic carbonate) (1 eq) and diamines (1 eq) in DMF was degassed with nitrogen for 15 minutes prior to heating. The reaction mixture was stirred at $70{ }^{\circ} \mathrm{C}$ under nitrogen atmosphere for up to 48 hours. After cooling to room temperature, the reaction mixture was added into acetone to precipitate the polymer, which was washed with acetone for three times. The purified polymer was dried at $60{ }^{\circ} \mathrm{C}$ under vacuum overnight prior to ${ }^{1} \mathrm{H}$ NMR, SEC, TGA, and DSC analysis.

\section{Poly(BBC-FBA)}

The polymerization of BBC (0.62 g, $2.6 \mathrm{mmol})$ and FBA $(0.33 \mathrm{~g}, 2.6 \mathrm{mmol})$ in DMF $(1 \mathrm{~mL})$ was carried out and the polymer was purified according to the general procedure. The purified polymer was obtained as a yellowish solid $(0.51 \mathrm{~g}$, yield $73 \%) .{ }^{1} \mathrm{H} \mathrm{NMR}(400 \mathrm{MHz}$, DMSO) $\delta 7.65$ (br, 2H), 6.11 (br, 2H), 5.13 (br, 1H), 4.90 - 4.76 (br, 1H), $4.10(\mathrm{br}, 4 \mathrm{H})$, 3.93 (br, 3H), 3.81 (br, 1H). SEC (DMF, PMMA standard) Mn: $11760 \mathrm{~g} \mathrm{~mol}^{-1}, \mathrm{Mw}_{\mathrm{w}}: 18960$ g mol-1, $\mathrm{PDI}=1.61$. Anal. Calcd. (\%) for $\mathrm{C}_{11} \mathrm{H}_{14} \mathrm{~N}_{2} \mathrm{O}_{6}$ : $\mathrm{C} ; 48.89 ; \mathrm{H}, 5.22 ; \mathrm{N}, 10.37$. Found: C, 48.89; H, 5.53; N, 10.68 .

\section{Poly(FBC-FBA)}

The polymerization of FBC $(0.50 \mathrm{~g}, 1.52 \mathrm{mmol})$ and FBA $(0.19 \mathrm{~g}, 1.52 \mathrm{mmol})$ in DMF (1 $\mathrm{mL}$ ) was carried out and the polymer was purified according to the general procedure. The purified polymer was obtained as a dark brown solid $(0.49 \mathrm{~g}$, yield $71 \%) .{ }^{1} \mathrm{H}$ NMR (400 MHz, DMSO) ס 7.62 (br, 2H), 6.37 (br, 2H), 6.11 (br, 2H), 5.01 (br, 1H), $4.82-4.71$ (br, 1H), 4.39 (br, 4H), $4.11(\mathrm{br}, 4 \mathrm{H}), 3.96-3.74(\mathrm{br}, 5 \mathrm{H}), 3.53-3.37(\mathrm{br}, 4 \mathrm{H})$. SEC (DMF, PMMA standard) $\mathrm{Mn}: 8730 \mathrm{~g} \mathrm{~mol}^{-1}, \mathrm{Mw}_{\mathrm{w}}: 17490 \mathrm{~g} \mathrm{~mol}^{-1}, \mathrm{PDI}=2.00$. Anal. Calcd. (\%) for $\mathrm{C}_{20} \mathrm{H}_{26} \mathrm{~N}_{2} \mathrm{O}_{10}$ : C; 52.86; $\mathrm{H}, 5.77 ; \mathrm{N}, 6.16$. Found: C, 53.04; $\mathrm{H}, 5.94 ; \mathrm{N}, 6.38$. 


\section{Poly(FBC-DAP)}

The polymerization of FBC $(10.0 \mathrm{~g}, 30 \mathrm{mmol})$ and DAP $(3.07 \mathrm{~g}, 30 \mathrm{mmol})$ in DMF $(15 \mathrm{~mL})$ was carried out and the polymer was purified according to the general procedure. The purified polymer was obtained as a brown solid (12.7 g, yield 97\%). ${ }^{1} \mathrm{H} \mathrm{NMR} \mathrm{(400} \mathrm{MHz,}$ DMSO) $\delta 7.10$ (br, 2H), 6.37 (br, 2H), 4.99 (br, 1H), 4.79 - 4.68 (br, 1H), 4.40 (br, 4H), 3.91 - 3.73 (br, 5H), $3.51-3.43(\mathrm{br}, 4 \mathrm{H}), 2.92$ (br, 4H), 1.37 (br, 4H), 1.21 (br, 2H). SEC (DMF, PMMA standard) Mn: $12730 \mathrm{~g} \mathrm{~mol}^{-1}, \mathrm{Mw}_{\mathrm{w}}: 22280 \mathrm{~g} \mathrm{~mol}^{-1}$, PDI = 1.75. Anal. Calcd. (\%) for $\mathrm{C}_{19} \mathrm{H}_{30} \mathrm{~N}_{2} \mathrm{O} 9$ : C; 53.02; $\mathrm{H}, 7.03$; N, 6.51. Found: C, 52.13; $\mathrm{H}, 7.26 ; \mathrm{N}, 7.72$.

\section{Poly(SuBC-FBA)}

The polymerization of SuBC $(0.63 \mathrm{~g}, 1.98 \mathrm{mmol})$ and FBA $(0.25 \mathrm{~g}, 1.98 \mathrm{mmol})$ in DMF $(1.25 \mathrm{~mL}$ ) was carried out and the polymer was purified according to the general procedure. The purified polymer was obtained as a brown solid $(0.62 \mathrm{~g}$, yield $71 \%) .{ }^{1} \mathrm{H}$ NMR (400 MHz, DMSO) ס 7.66 (br, 2H), 6.11 (br, 2H), 5.22 (br, 1H), 4.95 - 4.79 (br, 1H), $4.24(\mathrm{br}, 2 \mathrm{H}), 4.11(\mathrm{br}, 4 \mathrm{H}), 4.00-3.84(\mathrm{br}, 5 \mathrm{H}), 3.49$ (br, 2H), 2.58 (br, 4H). SEC (DMF, PMMA standard) $\mathrm{Mn}: 4870 \mathrm{~g} \mathrm{~mol}^{-1}, \mathrm{Mw}_{\mathrm{w}}: 7610 \mathrm{~g} \mathrm{~mol}^{-1}$, $\mathrm{PDI}=1.56$. Anal. Calcd. (\%) for $\mathrm{C}_{18} \mathrm{H}_{24} \mathrm{~N}_{2} \mathrm{O}_{11}: \mathrm{C} ; 48.65 ; \mathrm{H}, 5.44 ; \mathrm{N}, 6.30$. Found: C, 48.67; H, 5.60; N, 6.37.

\section{Representative procedure for the functionalization of hydroxyl groups of NIPUs}

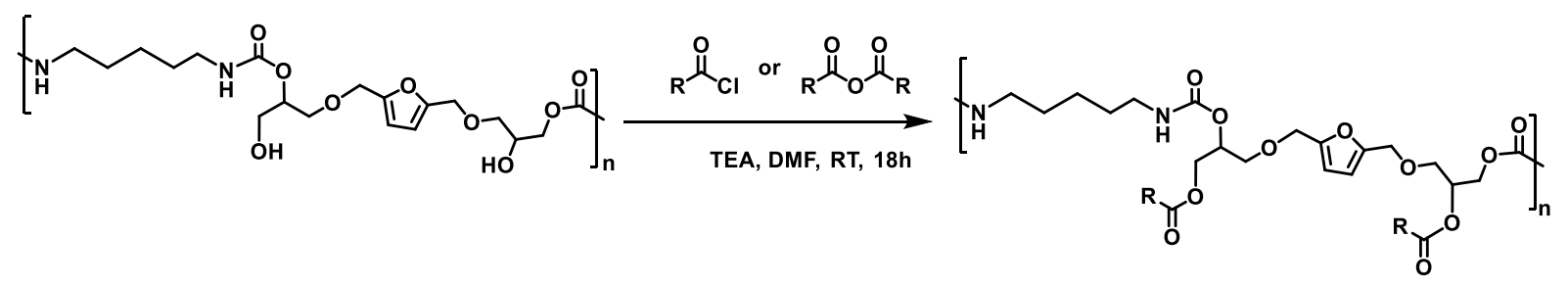

To a representative NIPU based on FBC and DAP $(1.00 \mathrm{~g}, 2.3 \mathrm{mmol})$ in anhydrous DMF $(25 \mathrm{~mL})$ solution was added to the desired acylation reagent $(5.0 \mathrm{mmol})$ followed by $(1.05$ $\mathrm{mL}, 7.5 \mathrm{mmol}$ ) triethylamine at room temperature. After $24 \mathrm{~h}$ of stirring, $10 \mathrm{~mL}$ of water was added at ambient temperature to quench the reaction. After removing the solvent, 
the residue was subsequently dissolved in DCM $(30 \mathrm{~mL})$. The organic layer was washed with dilute bicarbonate solution $(20 \mathrm{~mL})$ followed by water $(20 \mathrm{~mL})$. The organic layer was separated and dried with sodium sulfate. The solvent was filtered and evaporated to obtain the expected product.

\begin{tabular}{|l|l|l|l|}
\hline & Reactant & Yield $(\%)$ & ${ }^{1} \mathrm{H}$ MR characterization in $\mathrm{CDCl}_{3}$ \\
\hline Poly(FBC-DAP)-OAc & Acetic anhydride & 96 & acetylpeak: 2.07 and $2.04 \mathrm{ppm}$ \\
\hline Poly(FBC-DAP)-OC16 & Palmitic acid chloride & 95 & $\begin{array}{l}\text { Palmityl peak: } 2.28,1.58,1.41,1.25, \\
0.87 \mathrm{ppm}\end{array}$ \\
\hline
\end{tabular}

\section{General Procedures for Diels-Alder crosslinking of NIPUs with Bismaleimides} NIPU Gel

A solution of Poly(BBC-FBA) (100 mg, 1 eq based on mole of furan) and BM1 (25 mg, 0.5 eq based on mole of maleimide) in DMF $(0.5 \mathrm{~mL})$ was mixed homogeneously at room temperature. The reaction mixture in a glass vial was heated at $50^{\circ} \mathrm{C}$ for 1 hour until gel formation.

Preparation of crosslinked NIPU Coating films (representative)

Poly(FBC-DAP) was described as example for coating here. A solution of Poly(FBC-DAP) (200 mg, 1 eq based on mole of furan) and BM1 (40 mg, 0.5 eq) or BM2 (45.6 mg, 0.5 eq) in DMF (0.3 mL) was mixed homogeneously at room temperature. The reaction mixture was heated at $50{ }^{\circ} \mathrm{C}$ for $15-20$ minutes to achieve DA mixture with desirable viscosity. This solution was coated on the substrate (steel, aluminum, glass, or wood) using a film applicator. The coated substrate was cured at $50^{\circ} \mathrm{C}$ in an oven for at least 24 hours prior to characterizations. The absence of DMF in the dry coating film was confirmed by ${ }^{1} \mathrm{HNMR}$ after soaking of dry film in $\mathrm{CDCl}_{3}\left(0.1 \mathrm{~g}\right.$ of film in $0.5 \mathrm{ml}$ of $\left.\mathrm{CDCl}_{3}\right)$.

Similar procedure was used to produce crosslinked coating films of Poly(BBC-FBA), Poly(FBC-FBA), and Poly(SuBC-FBA) and BM1 or BM2 on different substrates. 


\section{Crosslink density calculation of NIPU-bismaleimide}

The crosslink density of NIPU-bismaleimide film was analyzed by using a dymanic mechanical analyzer according to a previously published method for NIPU.[5] The crosslinked polymer film was cut approximately into a $20 \mathrm{~mm}$ in length and $5 \mathrm{~mm}$ in width with a thickness of $0.02 \mathrm{~mm}$. The average molecular weight $\left(M_{c}\right)$ between crosslink nodes was calculated from the storage modulus ( $\left.E^{\prime}\right)$ of polymer at the rubbery state, the polymer density $(p)$ was determined to be $1.005 \mathrm{~g} / \mathrm{cm}^{3}$ by a density and specific gravity test in distilled water, the gas constant $(R)$, temperature $(T)$, and the Poisson ratio $(v)$ of 0.5 estimated for rubber. The equation was shown below.

$$
M c=\frac{2(1+v) p R T}{E^{\prime}}
$$

Next, the crosslink density $\left(\mathrm{v}_{\mathrm{c}}\right)$ was calculated as followed.

$$
V c=\frac{p}{M c}
$$

\begin{tabular}{|l|l|l|l|}
\hline NIPU-bismaleimide Film & E' (MPa) & Mc $(\mathrm{g} / \mathrm{mol})$ & $\mathrm{V}_{\mathrm{c}}\left(\mathrm{mol} / \mathrm{cm}^{3}\right)$ \\
\hline Poly(BBC-FBA)-BM1 & 33.5 & 260 & 0.00386 \\
\hline Poly(BBC-FBA)-BM2 & 31.9 & 274 & 0.00367 \\
\hline Poly(FBC-FBA)-BM1 & 34.3 & 254 & 0.00395 \\
\hline Poly(FBC-FBA)-BM2 & 36.8 & 237 & 0.00424 \\
\hline Poly(FBC-DAP)-BM1 & 22.0 & 390 & 0.00257 \\
\hline Poly(FBC-DAP)-BM2 & 21.8 & 395 & 0.00254 \\
\hline Poly(SuBC-FBA)-BM1 & 33.7 & 254 & 0.00394 \\
\hline Poly(SuBC-FBA)-BM2 & 27.0 & 318 & 0.00315 \\
\hline
\end{tabular}




\section{Scheme S1}
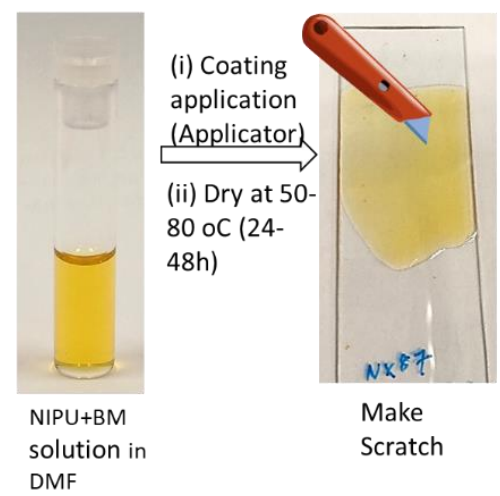

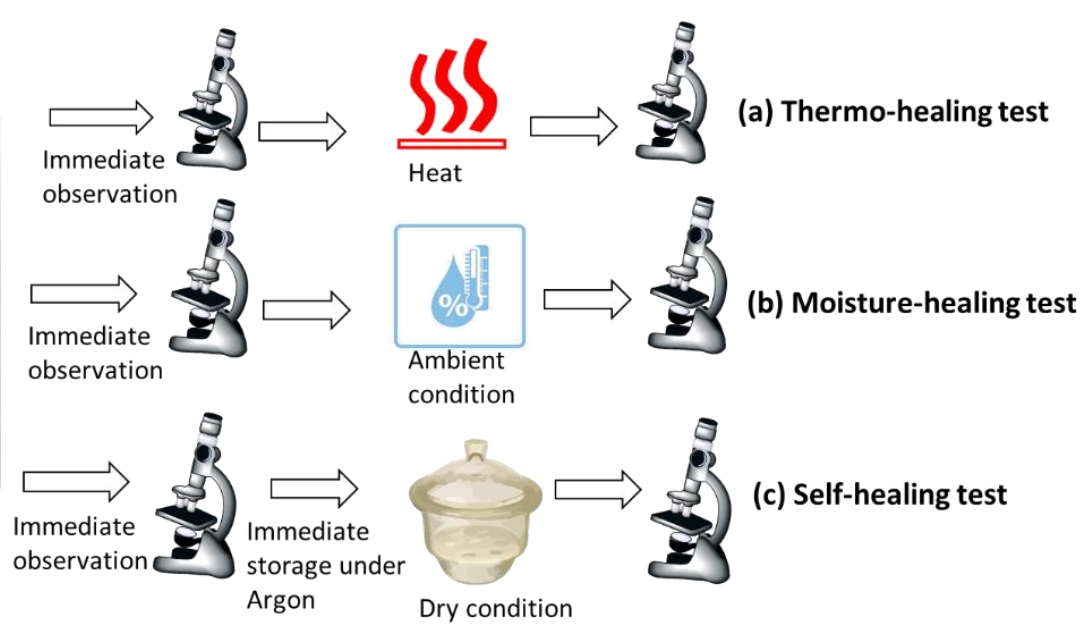

Scheme S1. Sample preparation and evaluation of healing properties of NIPU-BM crosslinked dry coating films under different conditions. Coatings were dried in oven at $50-80{ }^{\circ} \mathrm{C}$ for $24 \mathrm{~h}$ before it was cooled down to RT and scratched the surface. The absence of DMF in the dry coating film was confirmed by ${ }^{1} \mathrm{H}$ NMR after soaking of dry film in $\mathrm{CDCl}_{3}$ $\left(0.1 \mathrm{~g}\right.$ of film in $0.5 \mathrm{ml}$ of $\left.\mathrm{CDCl}_{3}\right)$. The final dry coating film thincness was $\sim 30 \mu \mathrm{m}$. Optical mocroscopy (Nikon Eclipse Ci-L microscope system) was used for the healing evaluation of scratch. 


\section{Vl. Table S1: Details of polymerization and polymers.}

\begin{tabular}{|c|c|c|c|c|c|c|c|c|c|c|c|}
\hline \multirow[b]{2}{*}{ Polymer } & \multicolumn{3}{|c|}{ Furan Conversion } & \multicolumn{3}{|c|}{ Cyclic Carbonate Conversion } & \multirow[b]{2}{*}{$\begin{array}{c}\mathrm{M}_{\mathrm{n}}^{\mathrm{C}} \\
\left(\mathrm{g} \mathrm{mol}^{-1}\right)\end{array}$} & \multirow[b]{2}{*}{$\begin{array}{c}\mathrm{M}_{\mathrm{w}}{ }^{\mathrm{C}} \\
\left(\mathrm{g} \mathrm{mol}^{-1}\right)\end{array}$} & \multirow[b]{2}{*}{$\bigoplus^{\mathrm{C}}$} & \multirow[b]{2}{*}{$\begin{array}{l}\mathrm{T}_{\mathrm{g}}^{\mathrm{d}} \\
\left({ }^{\circ} \mathrm{C}\right)\end{array}$} & \multirow[b]{2}{*}{$\begin{array}{l}\mathrm{T}_{\mathrm{g}}^{\mathrm{e}} \\
\left({ }^{\circ} \mathrm{C}\right)\end{array}$} \\
\hline & $p^{a}$ & $\begin{array}{c}\text { Degree of } \\
\text { polymerization } \\
\left(\overline{X_{2 n}}\right)\end{array}$ & $\begin{array}{c}{\overline{M_{n}}}^{\mathrm{b}} \\
\left(\mathrm{g} \mathrm{mol}^{-1}\right)\end{array}$ & $\mathrm{p}^{\mathrm{a}}$ & $\begin{array}{c}\text { Degree of } \\
\text { polymerization } \\
\left(\overline{X_{2 n}}\right)\end{array}$ & $\begin{array}{c}{\overline{M_{n}}}^{\mathrm{b}} \\
\left(\mathrm{g} \mathrm{mol}^{-1}\right)\end{array}$ & & & & & \\
\hline $\begin{array}{c}\text { Poly(BBC- } \\
\text { FBA) }\end{array}$ & 0.975 & 40 & 10810 & 0.972 & 36 & 9728 & 11800 & 18950 & 1.61 & 40 & 38 \\
\hline $\begin{array}{c}\text { Poly(FBC- } \\
\text { FBA) }\end{array}$ & 0.943 & 17 & 7725 & 0.923 & 13 & 5907 & 8700 & 17500 & 2.00 & 38 & 34 \\
\hline $\begin{array}{c}\text { Poly(FBC- } \\
\text { DAP) }\end{array}$ & 0.959 & 24 & 10330 & 0.950 & 20 & 8609 & 10900 & 19170 & 1.75 & 15 & 6 \\
\hline $\begin{array}{c}\text { Poly(SuBC- } \\
\text { FBA) }\end{array}$ & 0.940 & 16 & 7110 & 0.924 & 13 & 5777 & 4900 & 7600 & 1.56 & 33 & 15 \\
\hline
\end{tabular}

${ }^{a}$ Calculated based on Carothers' equation ${ }^{\mathrm{x}} \overline{X_{2 n}}=1 /(1-p)$, where $\overline{X_{2 n}}$ is degree of polymerization and $p$ is monomer conversion (furan or cyclic carbonate) based on ${ }^{1} \mathrm{H}$ NMR; ${ }^{b}$ calculated by multiplying $\overline{X_{2 n}}$ and molar masses of repeating unit of polymer ${ }^{\circ}$ obtained from SEC (DMF) using PMMA calibration; ${ }^{\mathrm{d}} \mathrm{dry}$ NIPU sampleswere analyzed by DSC $\left(2^{\text {nd }}\right.$ or $3^{\text {rd }}$ heating curve $)$ immediately after drying at $50^{\circ} \mathrm{C}$ under vacuum overnightand ${ }^{\mathrm{e}}$ moistened NIPU samples were analyzed by DSC after three daysin a humidity chamber at $\mathrm{RH}>95 \%$. 
VII. $1 \mathrm{H}$ NMR spectra, TGA and DCS plots of NIPUs

a)
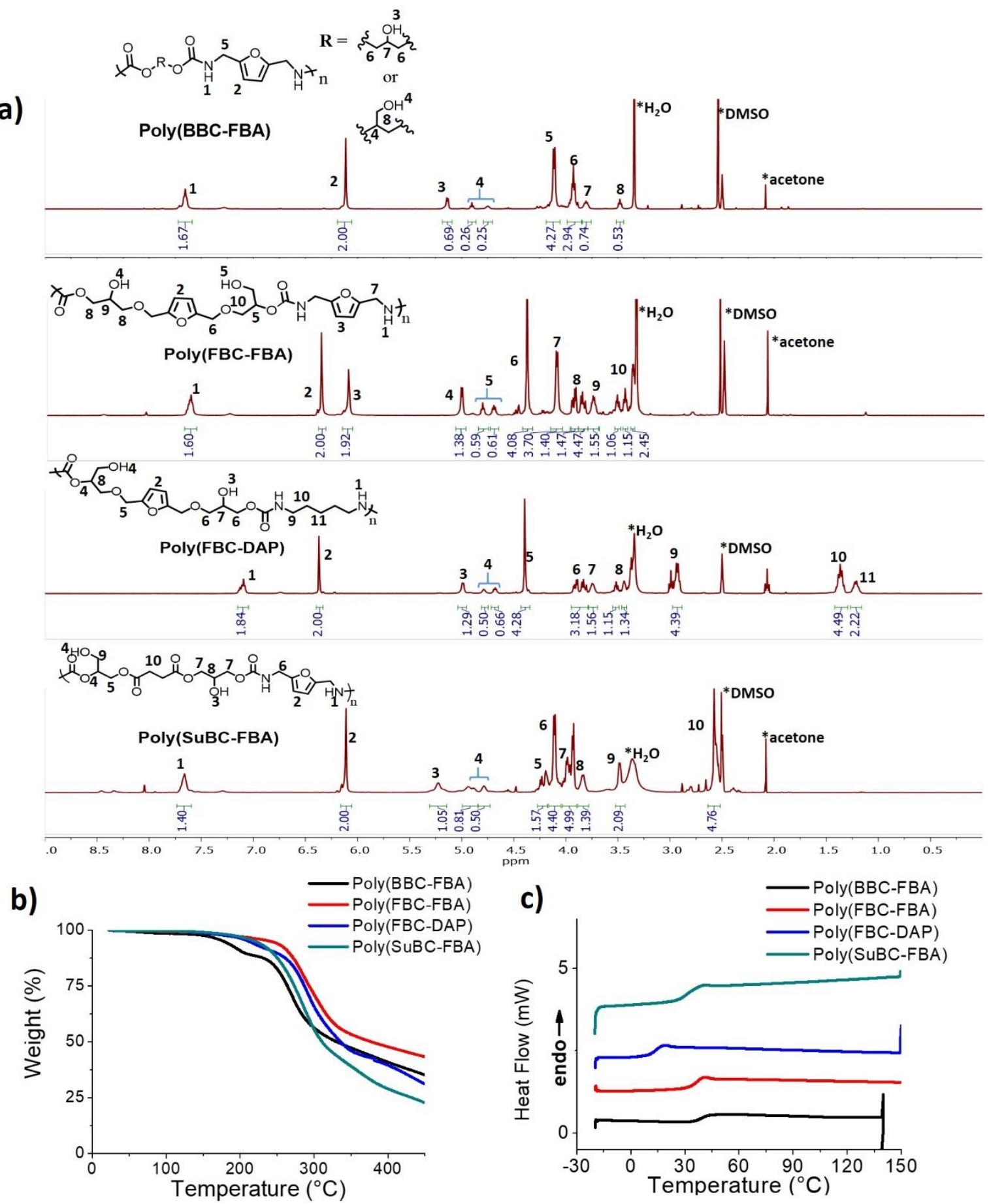

Figure S1. a) ${ }^{1} \mathrm{H}$ NMR spectra, b) overlay thermogravimetric analysis plots and c) differential scanning calorimetry plots of all four NIPUs. 

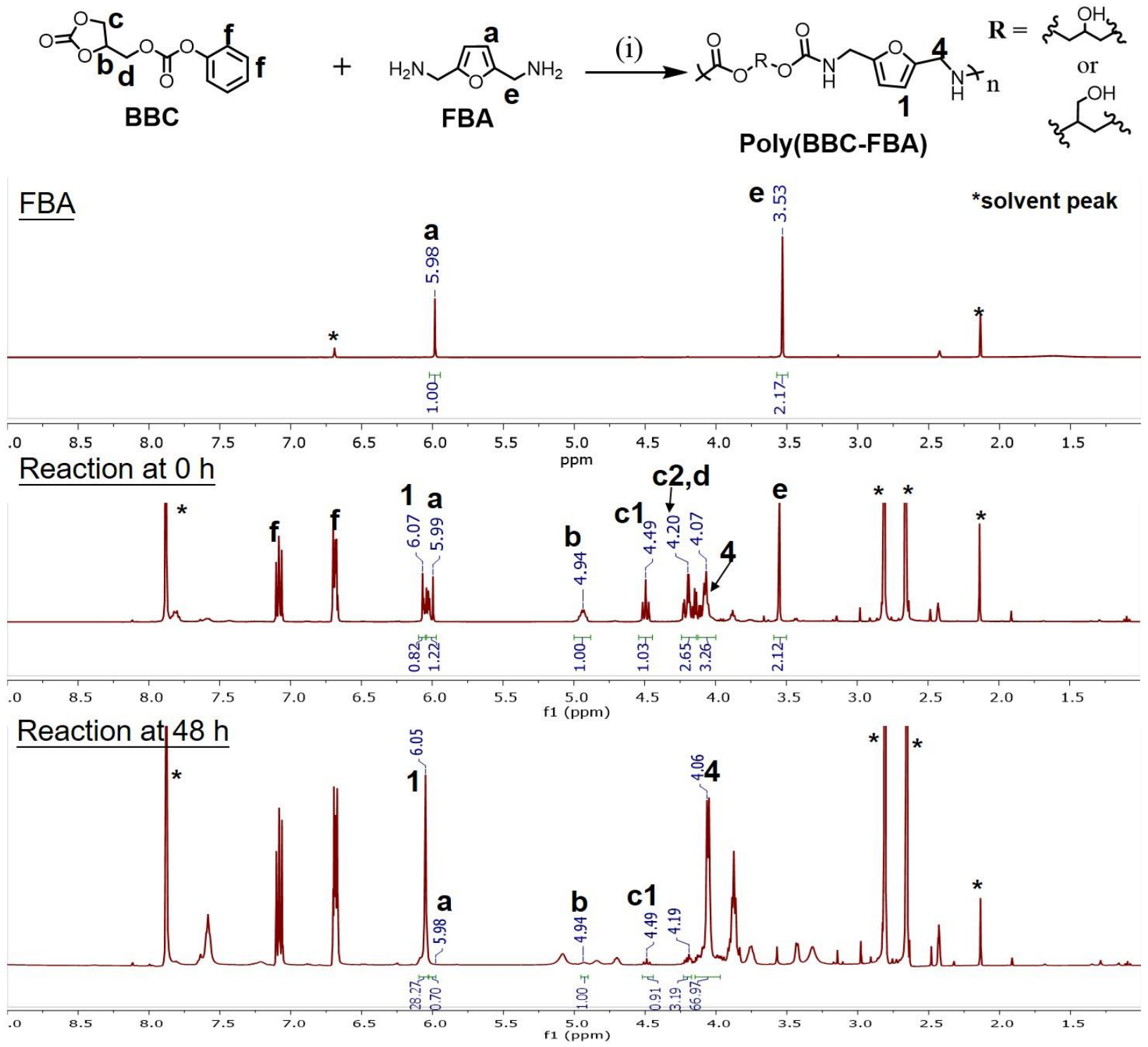

Figure S2. ${ }^{1} \mathrm{H}$ NMR spectra of polymerization of BBC and FBA at 0 hour and at 48 hours in d6-dmso. Mesitylene peak at $2.10 \mathrm{ppm}$ was used as reference peak. Formation of oligomers was observed at 0 hour due to reaction happened during nitrogen degassing at room temperature. The degree of advancement of reaction, $p$ was calculated from the equation: $p=\left[\mathrm{H}_{1}\right] /\left[\left(\mathrm{H}_{\mathrm{a}}\right)+\left(\mathrm{H}_{1}\right)\right]$, where $\mathrm{H}_{1}$ is integral of proton 1 of polymer, and $\mathrm{H}_{\mathrm{a}}$ is the integral of proton a in furan; or $p=\left[\mathrm{H}_{4}\right] /\left[\left(\mathrm{Hb}_{b}+\mathrm{H}_{\mathrm{c} 1}\right)+\left(\mathrm{H}_{4}\right)\right]$, where $\mathrm{H}_{4}$ is integral of proton 4 of polymer, and $\mathrm{Hb}_{\mathrm{b}}$ and $\mathrm{H}_{\mathrm{c} 1}$ are the integrals of proton $\mathrm{b}$ and $\mathrm{c} 1$ of cyclic carbonate after polymerization. 

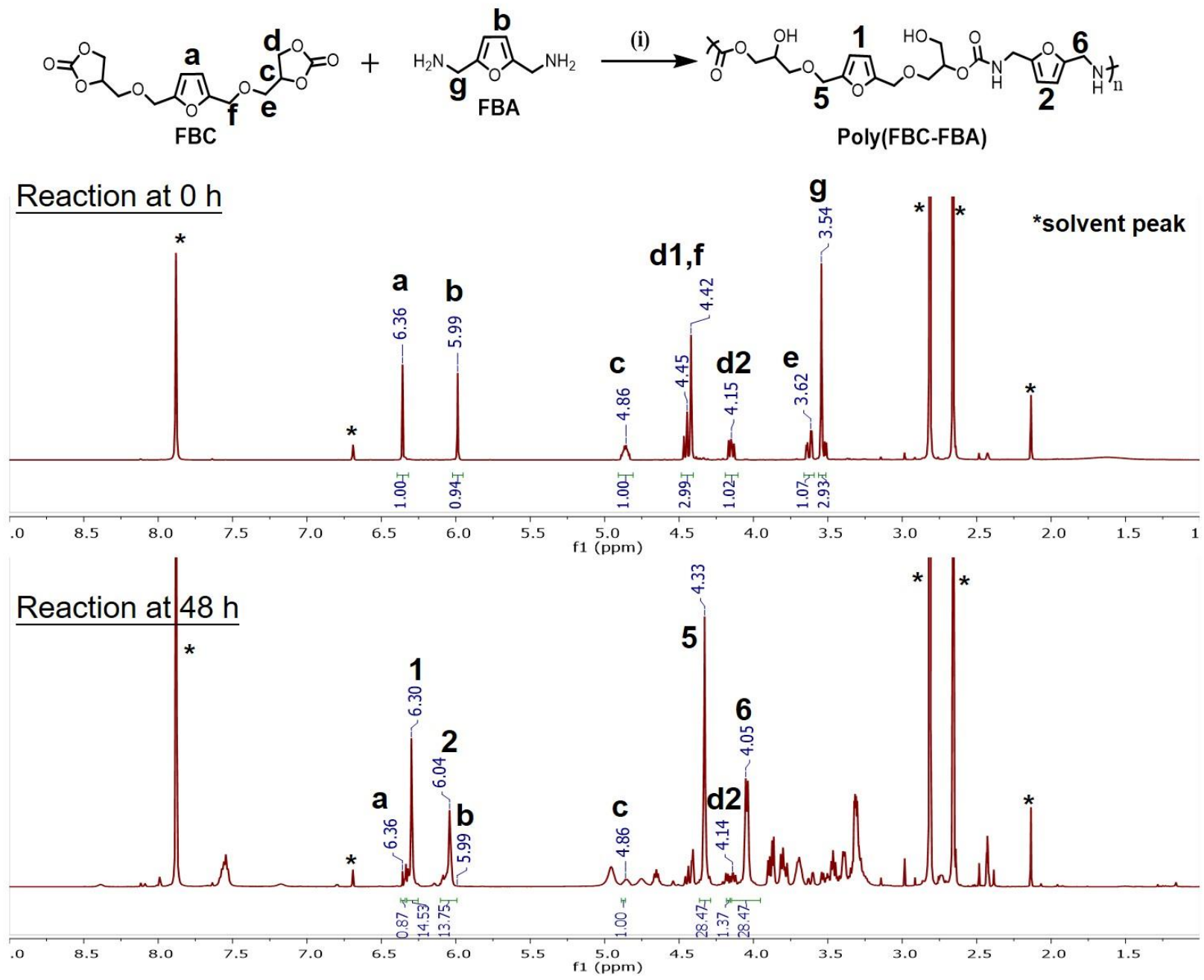

Figure S3. ${ }^{1} \mathrm{H}$ NMR spectra of polymerization of FBC and FBA at 0 hour and at 48 hours in d6-dmso. Mesitylene peak at $6.70 \mathrm{ppm}$ was used as reference peak. The degree of advancement of reaction, $p$ was calculated from the equation: $p=\left[\mathrm{H}_{1}\right] /\left[\left(\mathrm{H}_{\mathrm{a}}\right)+\left(\mathrm{H}_{1}\right)\right]$, where $\mathrm{H}_{1}$ is integral of proton 1 of polymer, and $\mathrm{Ha}_{\mathrm{a}}$ is the integral of proton a in furan; or $p=$ $\left[\mathrm{H}_{6}\right] /\left[\left(\mathrm{H}_{\mathrm{c}}+\mathrm{H}_{\mathrm{d} 2}\right)+\left(\mathrm{H}_{6}\right)\right]$, where $\mathrm{H}_{6}$ is integral of proton 6 of polymer, and $\mathrm{H}_{\mathrm{c}}$ and $\mathrm{H}_{\mathrm{d} 2}$ are the integrals of proton $\mathrm{c}$ and $\mathrm{d} 2$ of cyclic carbonate after polymerization. 

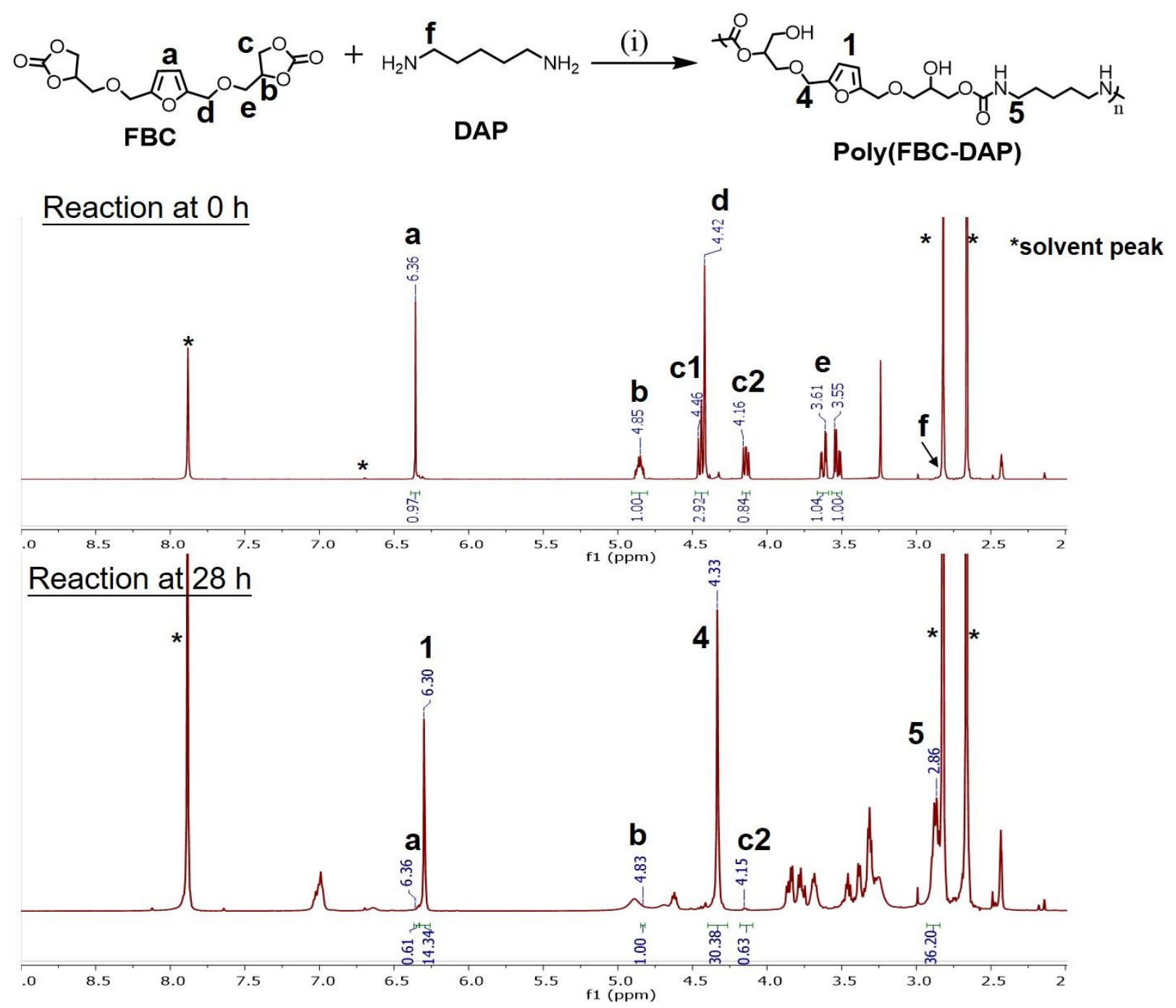

Figure S4. ${ }^{1} \mathrm{H}$ NMR spectra of polymerization of FBC and DAP at 0 hour and at 28 hours in d6-dmso. Mesitylene peak at $6.70 \mathrm{ppm}$ was used as reference peak. The degree of advancement of reaction, $p$ was calculated from the equation: $p=\left[\mathrm{H}_{1}\right] /\left[\left(\mathrm{H}_{\mathrm{a}}\right)+\left(\mathrm{H}_{1}\right)\right]$, where $\mathrm{H}_{1}$ is integral of proton 1 of polymer, and $\mathrm{H}_{\mathrm{a}}$ is the integral of proton a in furan; or $p=$ $\left[\mathrm{H}_{4}\right] /\left[\left(\mathrm{H}_{b}+\mathrm{H}_{\mathrm{c} 2}\right)+\left(\mathrm{H}_{4}\right)\right]$, where $\mathrm{H}_{4}$ is integral of proton 4 of polymer, and $\mathrm{Hb}_{b}$ and $\mathrm{H}_{\mathrm{c} 2}$ are the integrals of proton $b$ and $c 2$ of cyclic carbonate after polymerization. 


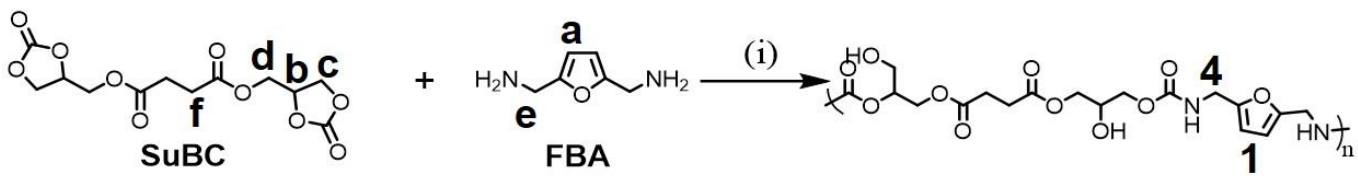

$\underline{\text { Reaction at } \mathrm{O} \mathrm{h}}$
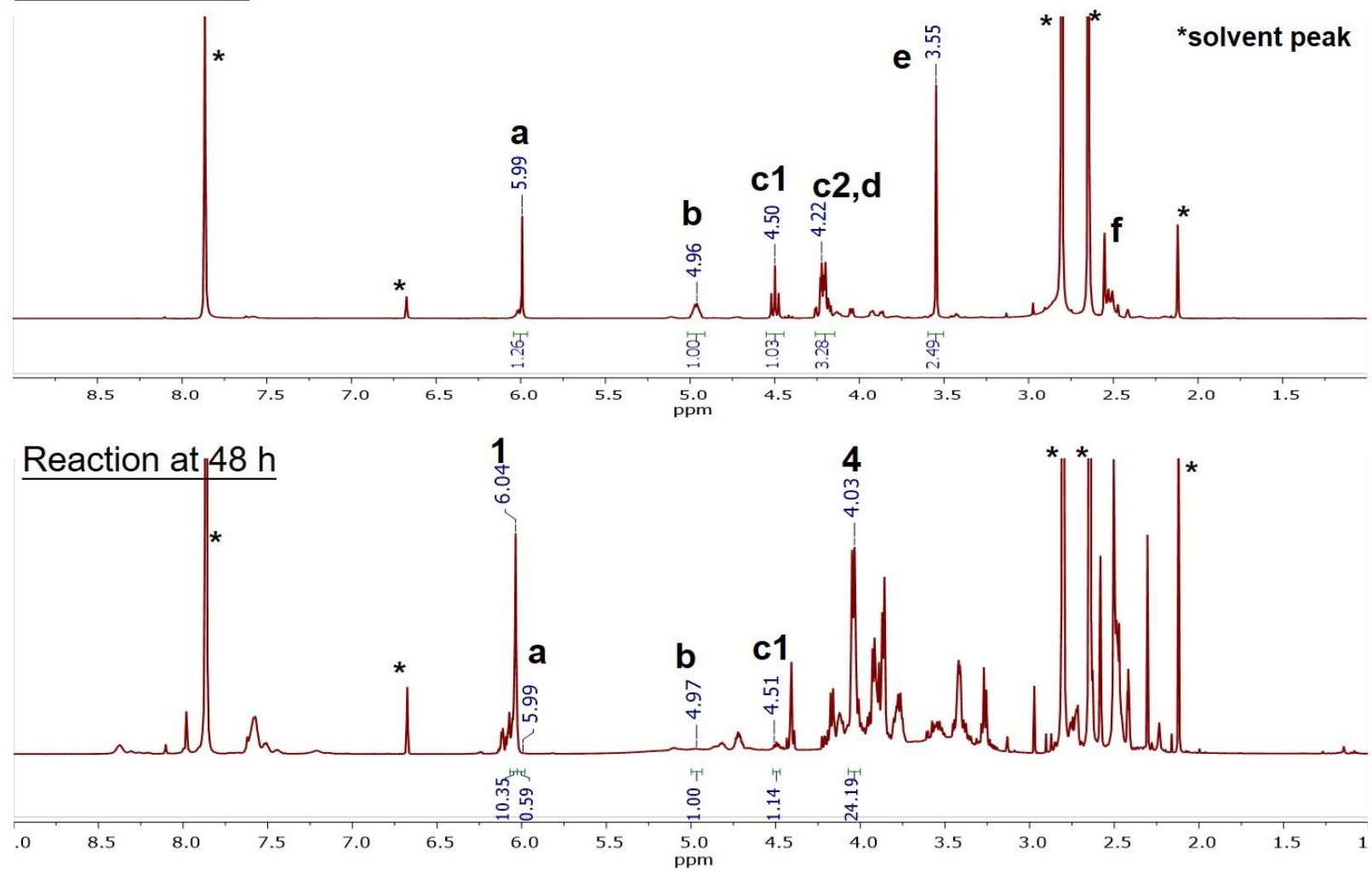

Figure S5. ${ }^{1} \mathrm{H}$ NMR spectra of polymerization of SuBC and FBA at 0 hour and at 48 hours in d6-dmso. Mesitylene peak at $6.70 \mathrm{ppm}$ was used as reference peak. The degree of advancement of reaction, $p$ was calculated from the equation: $p=\left[\mathrm{H}_{1}\right] /\left[\left(\mathrm{H}_{2}\right)+\left(\mathrm{H}_{1}\right)\right]$, where $\mathrm{H}_{1}$ is integral of proton 1 of polymer, and $\mathrm{Ha}_{\mathrm{a}}$ is the integral of proton a in furan; or $p=$ $\left[\mathrm{H}_{4}\right] /\left[\left(\mathrm{Hb}_{b}+\mathrm{H}_{c 1}\right)+\left(\mathrm{H}_{4}\right)\right]$, where $\mathrm{H}_{4}$ is integral of proton 4 of polymer, and $\mathrm{Hb}_{b}$ and $\mathrm{H}_{c 1}$ are the integrals of proton $\mathrm{b}$ and $\mathrm{c} 1$ of cyclic carbonate after polymerization. 


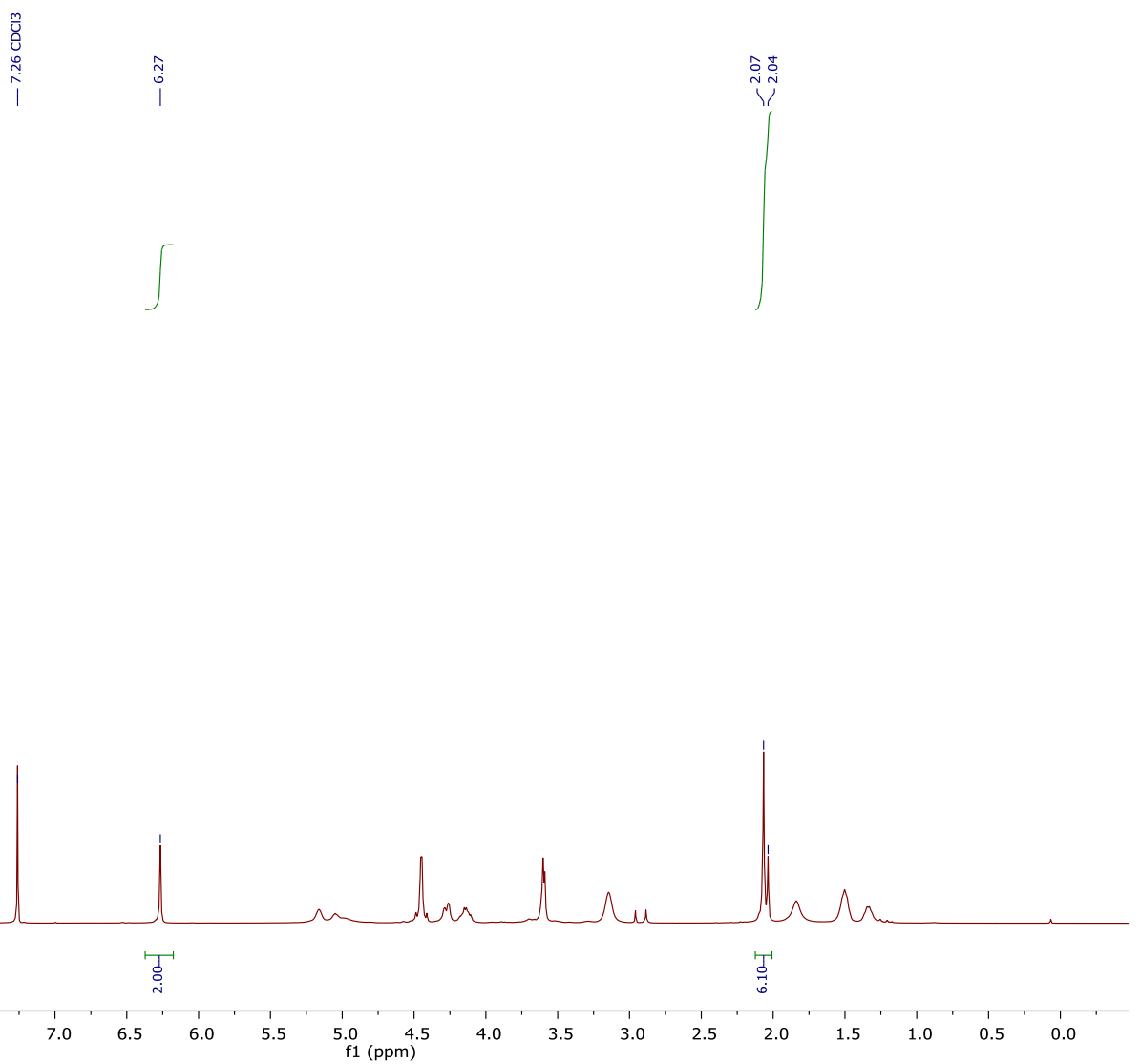

Figure S6. ${ }^{1} \mathrm{H}$ NMR spectrum of poly(FBC-DAP)-OAc in $\mathrm{CDCl}_{3}$. 


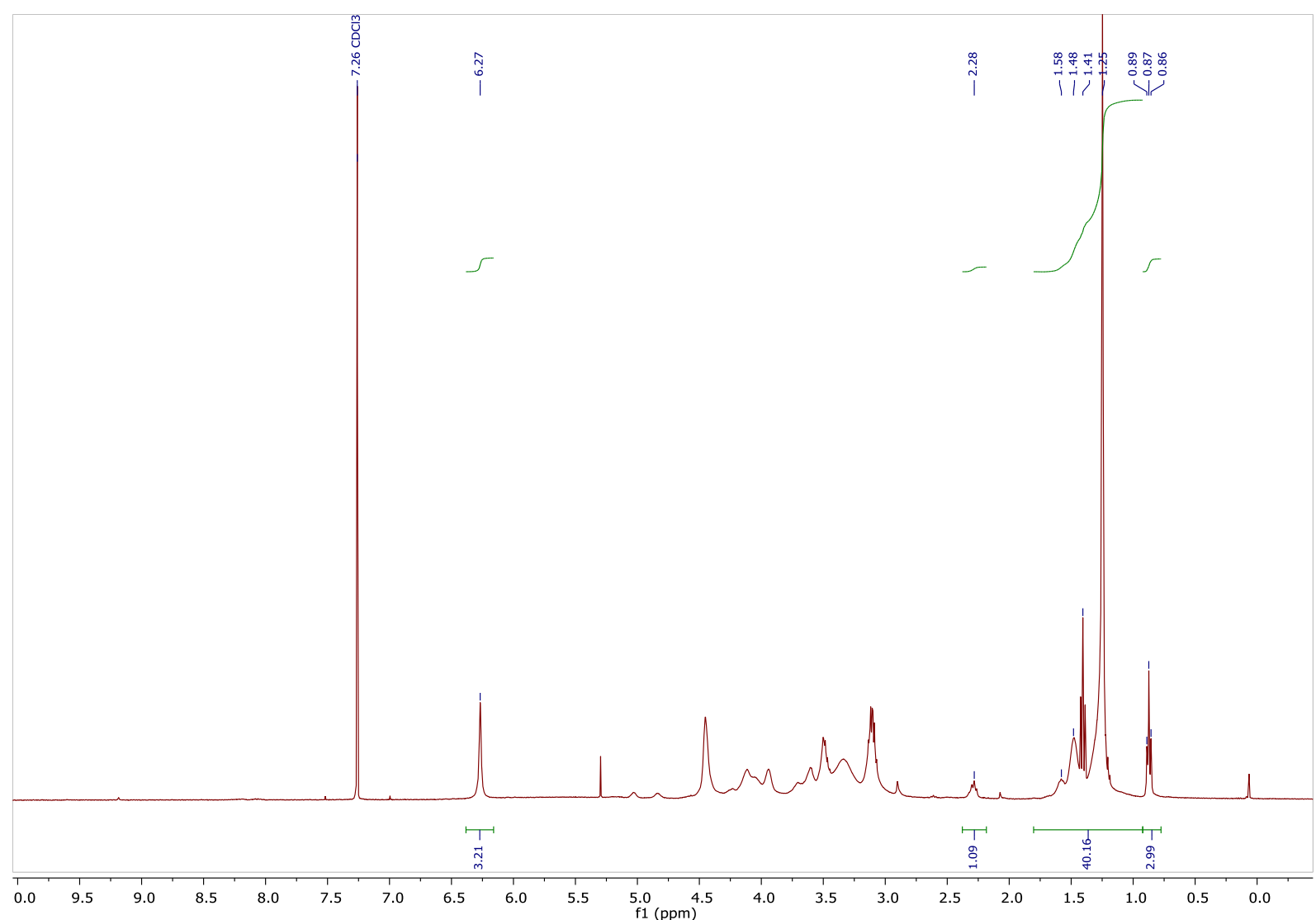

Figure S7. ${ }^{1} \mathrm{H}$ NMR spectrum of poly(FBC-DAP)-OC16 in $\mathrm{CDCl}_{3}$. 
VIII. DSC plots of moistened NIPUs

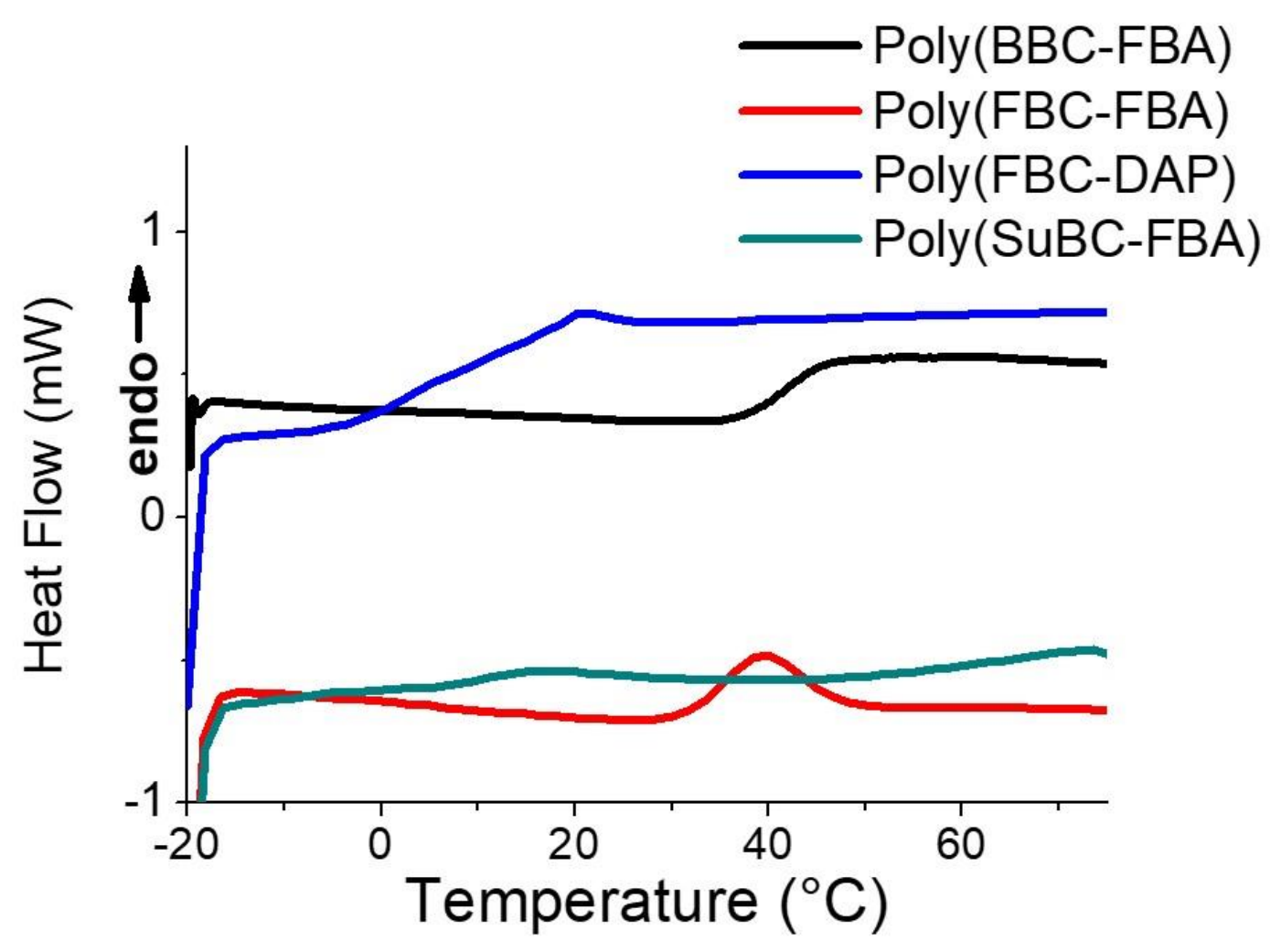

Figure S8. DSC plot of all four moistened NIPUs after exposure to moisture in a humidity chamber $(\mathrm{RH}>95 \%)$ for 3 days. 
IX. ${ }^{1} \mathrm{H}$ NNR spectra of NIPUs crosslinked with BM

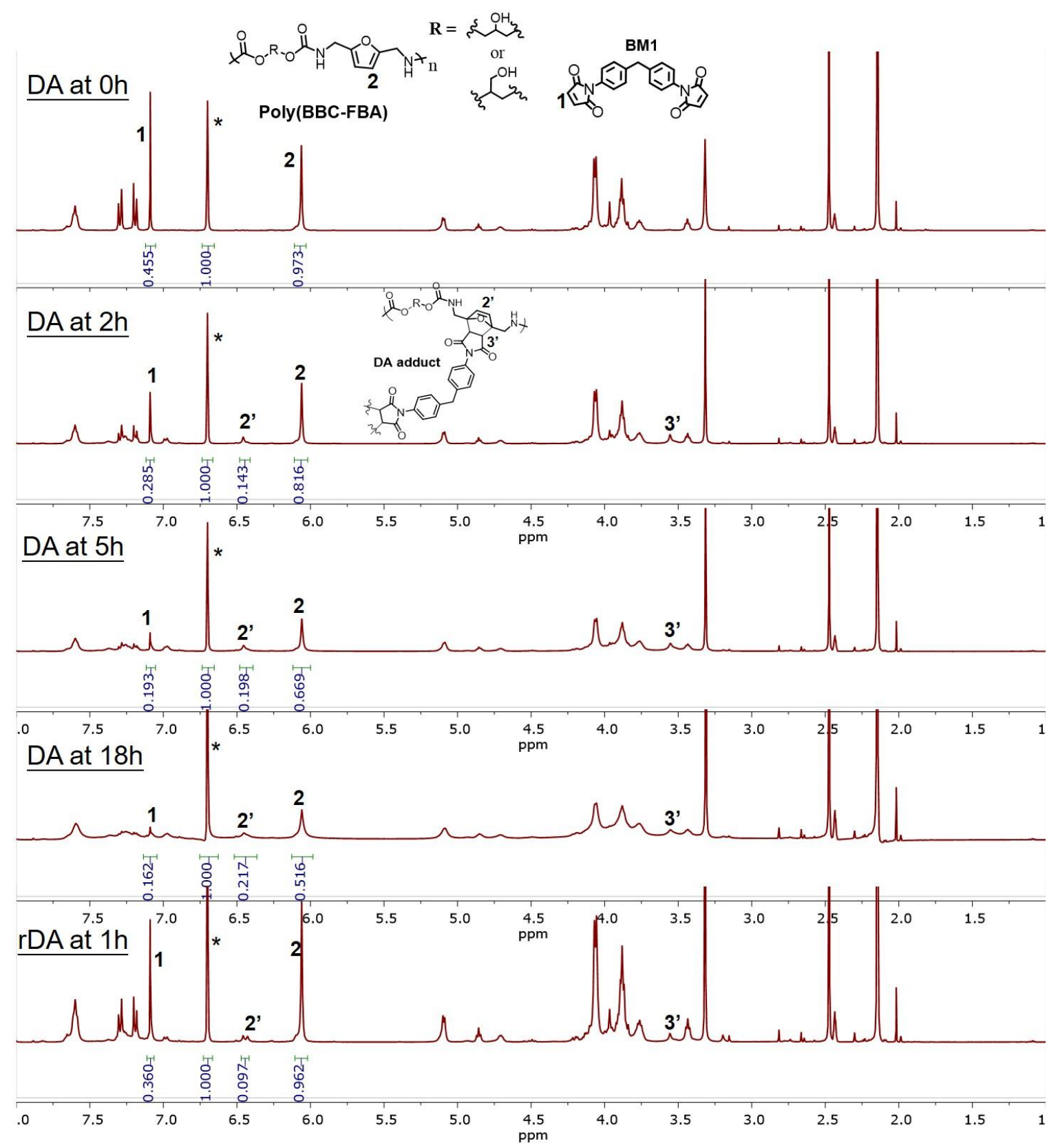

Figure S9. ${ }^{1} \mathrm{H}$ NMR spectra of Poly(BBC-FBA) and BM1 (furan:maleimide $=1: 0.5$ ) solution in d6-dmso. The DA reaction was carried out at $50^{\circ} \mathrm{C}$ for 18 hours and $\mathrm{rDA}$ reaction was carried out at $110^{\circ} \mathrm{C}$ for 1 hour. ${ }^{*}$ denotes the mesitylene peak which was used as internal standard. 

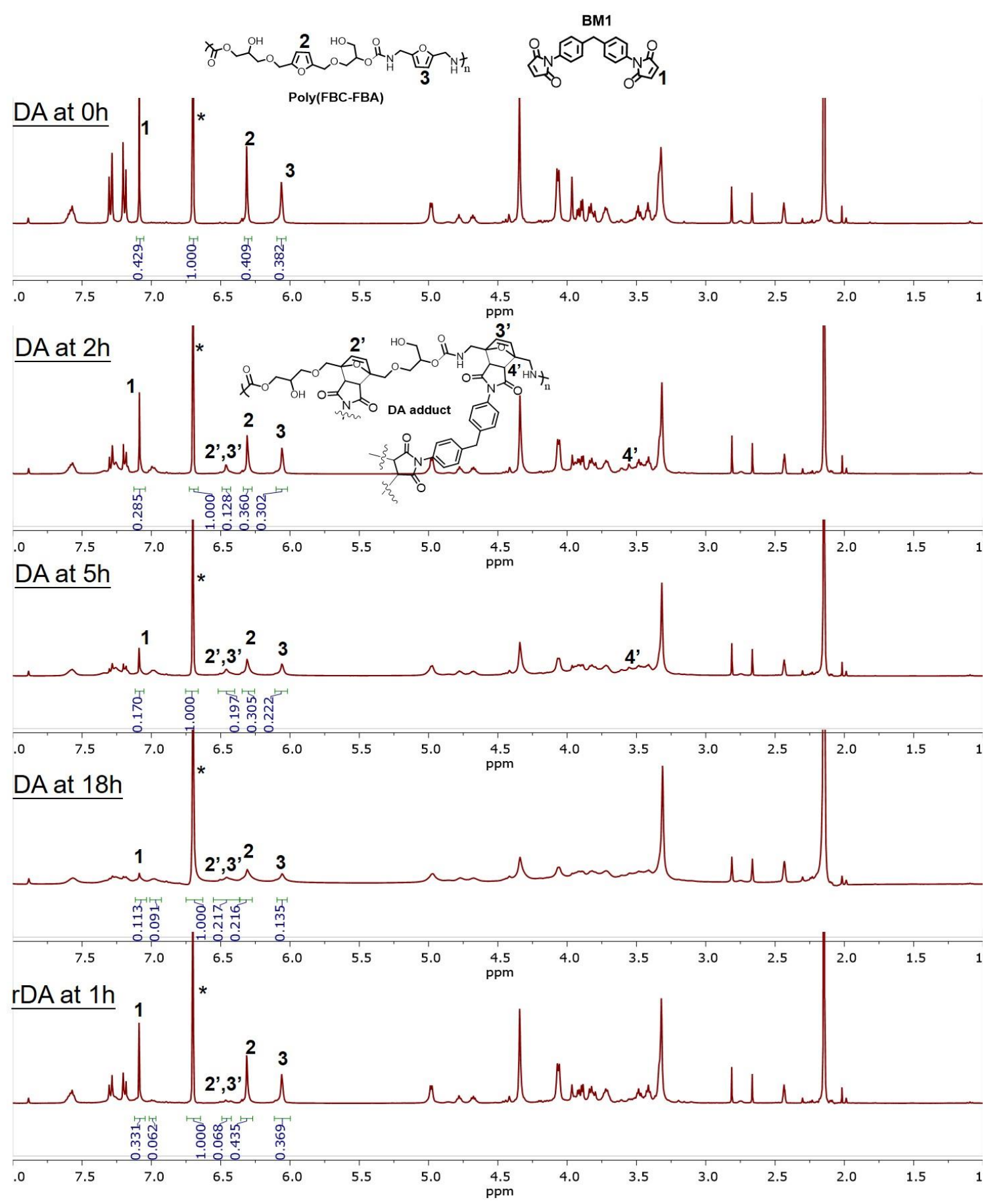

Figure S10. ${ }^{1} \mathrm{H}$ NMR spectra of Poly(FBC-FBA) and BM1 (furan:maleimide $=1: 0.5$ ) solution in d6-dmso. The DA reaction was carried out at $50^{\circ} \mathrm{C}$ for 18 hours and rDA reaction was carried out at $110^{\circ} \mathrm{C}$ for 1 hour. * denotes the mesitylene peak which was used as internal standard. 


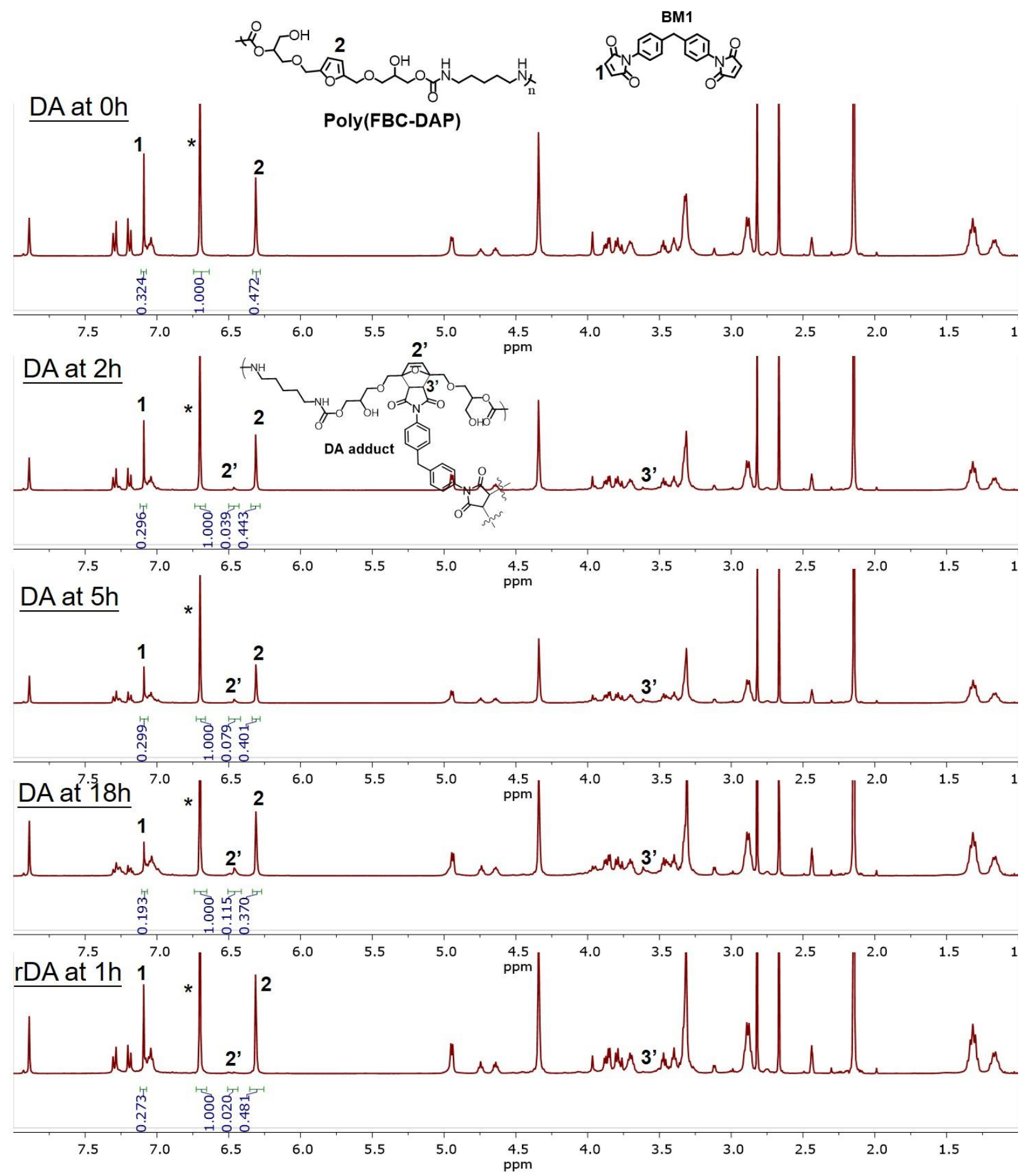

Figure S11. ${ }^{1} \mathrm{H}$ NMR spectra of Poly(FBC-DAP) and BM1 (furan:maleimide = 1:0.5) solution in d6-dmso. The DA reaction was carried out at $50^{\circ} \mathrm{C}$ for 18 hours and rDA reaction was carried out at $110{ }^{\circ} \mathrm{C}$ for 1 hour. * denotes the mesitylene peak which was used as internal standard. 

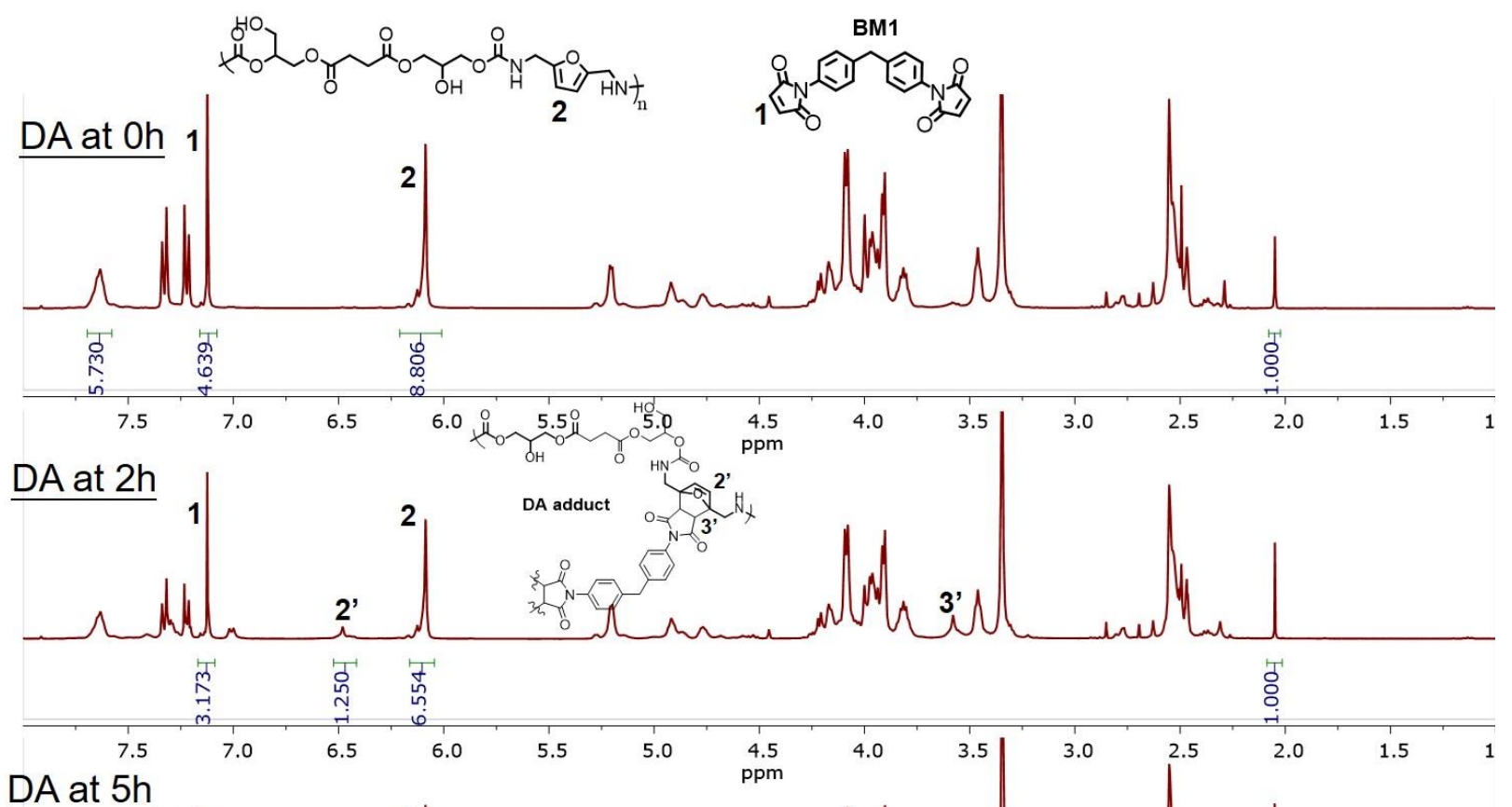

$\underline{\mathrm{DA} \text { at } 5 \mathrm{~h}}$

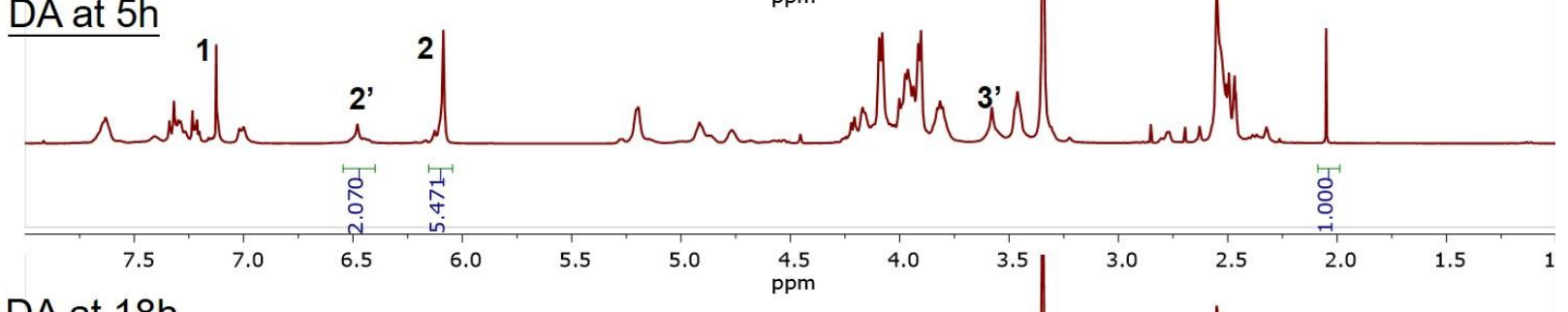

DA at $18 \mathrm{~h}$

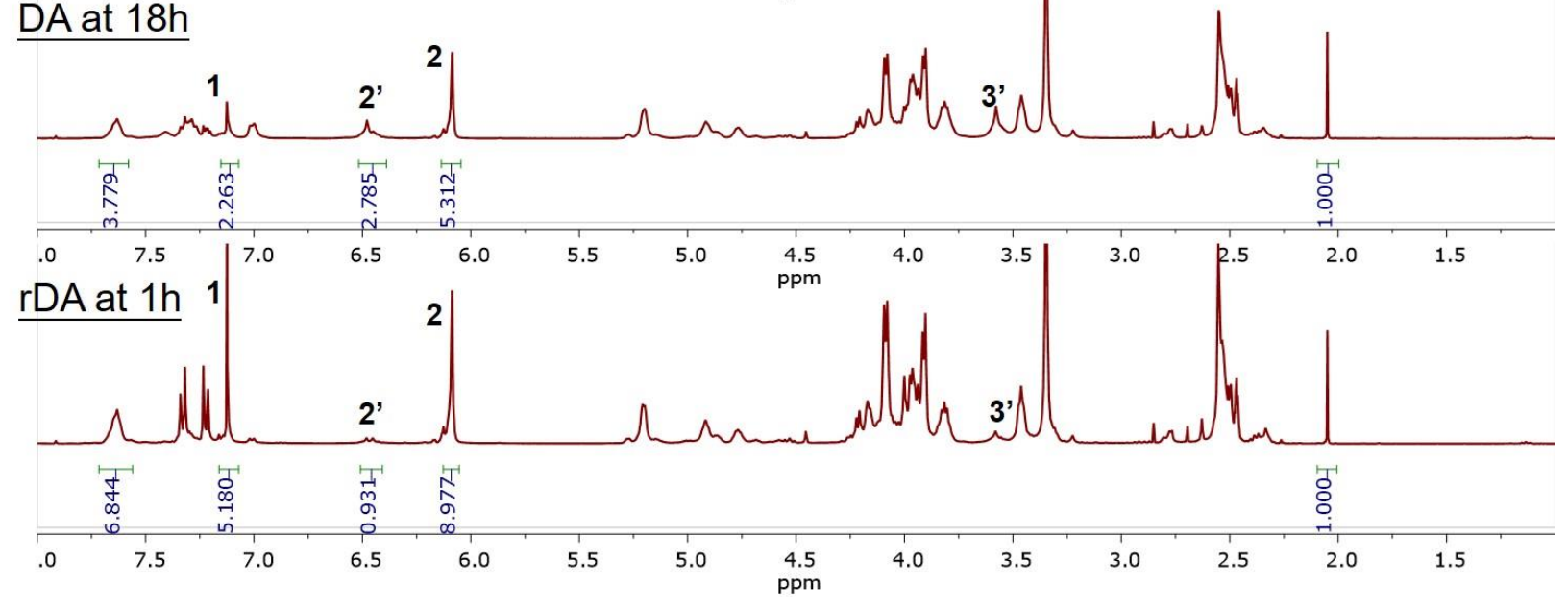

Figure S12. ${ }^{1} \mathrm{H}$ NMR spectra of Poly(SuBC-FBA) and BM1 (furan:maleimide = 1:0.5) solution in d6-dmso. The DA reaction was carried out at $50^{\circ} \mathrm{C}$ for 18 hours and rDA reaction was carried out at $110^{\circ} \mathrm{C}$ for 1 hour. 

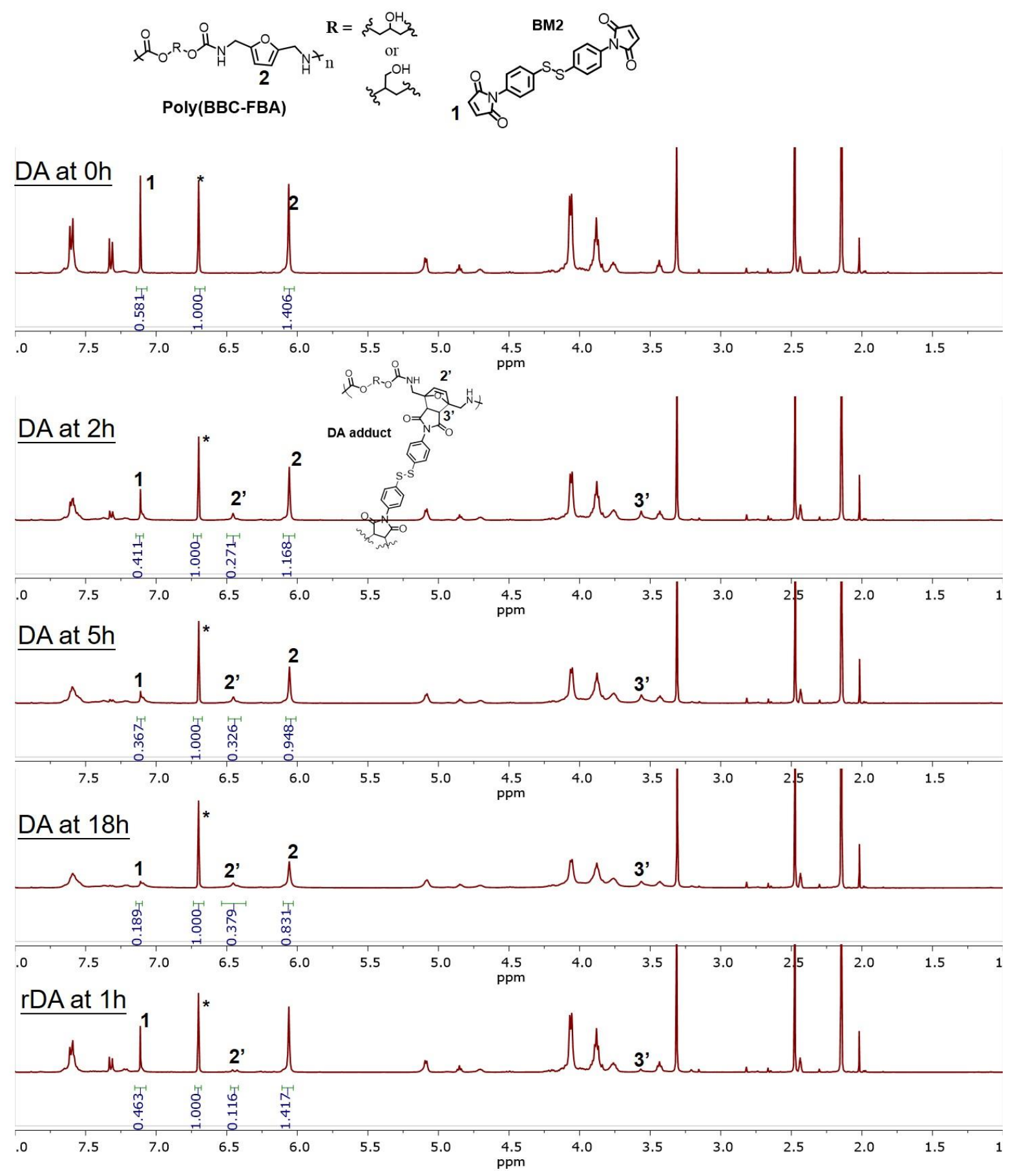

Figure S13. ${ }^{1} \mathrm{H}$ NMR spectra of Poly(BBC-FBA) and BM2 (furan:maleimide = 1:0.5) solution in d6-dmso. The DA reaction was carried out at $50^{\circ} \mathrm{C}$ for 18 hours and $\mathrm{rDA}$ reaction was carried out at $110^{\circ} \mathrm{C}$ for 1 hour. ${ }^{*}$ denotes the mesitylene peak which was used as internal standard. 


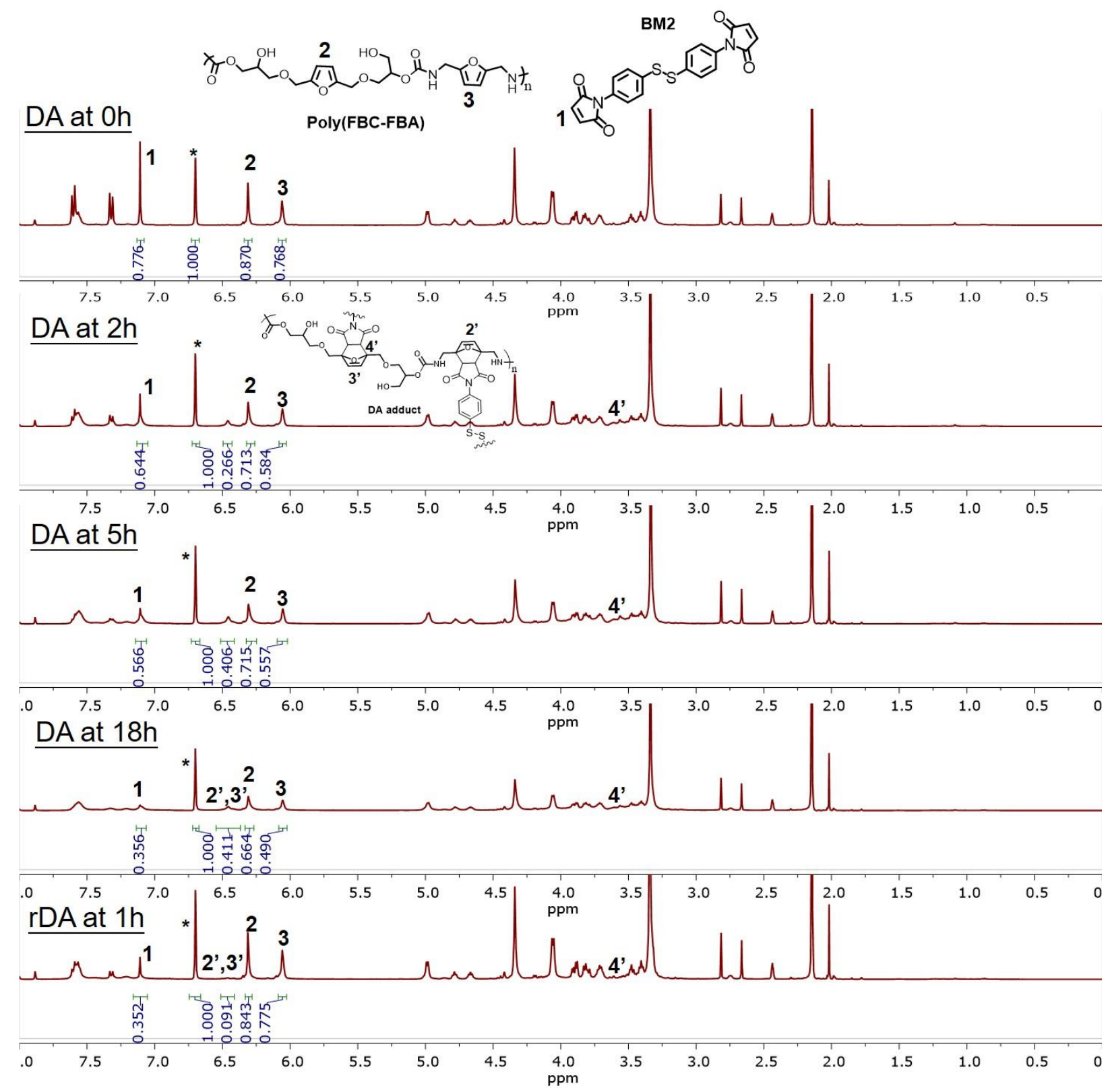

Figure S14. ${ }^{1 H}$ NMR spectra of Poly(FBC-FBA) and BM2 (furan:maleimide = 1:0.5) solution in d6-dmso. The DA reaction was carried out at $50^{\circ} \mathrm{C}$ for 18 hours and rDA reaction was carried out at $110{ }^{\circ} \mathrm{C}$ for 1 hour. * denotes the mesitylene peak which was used as internal standard. 


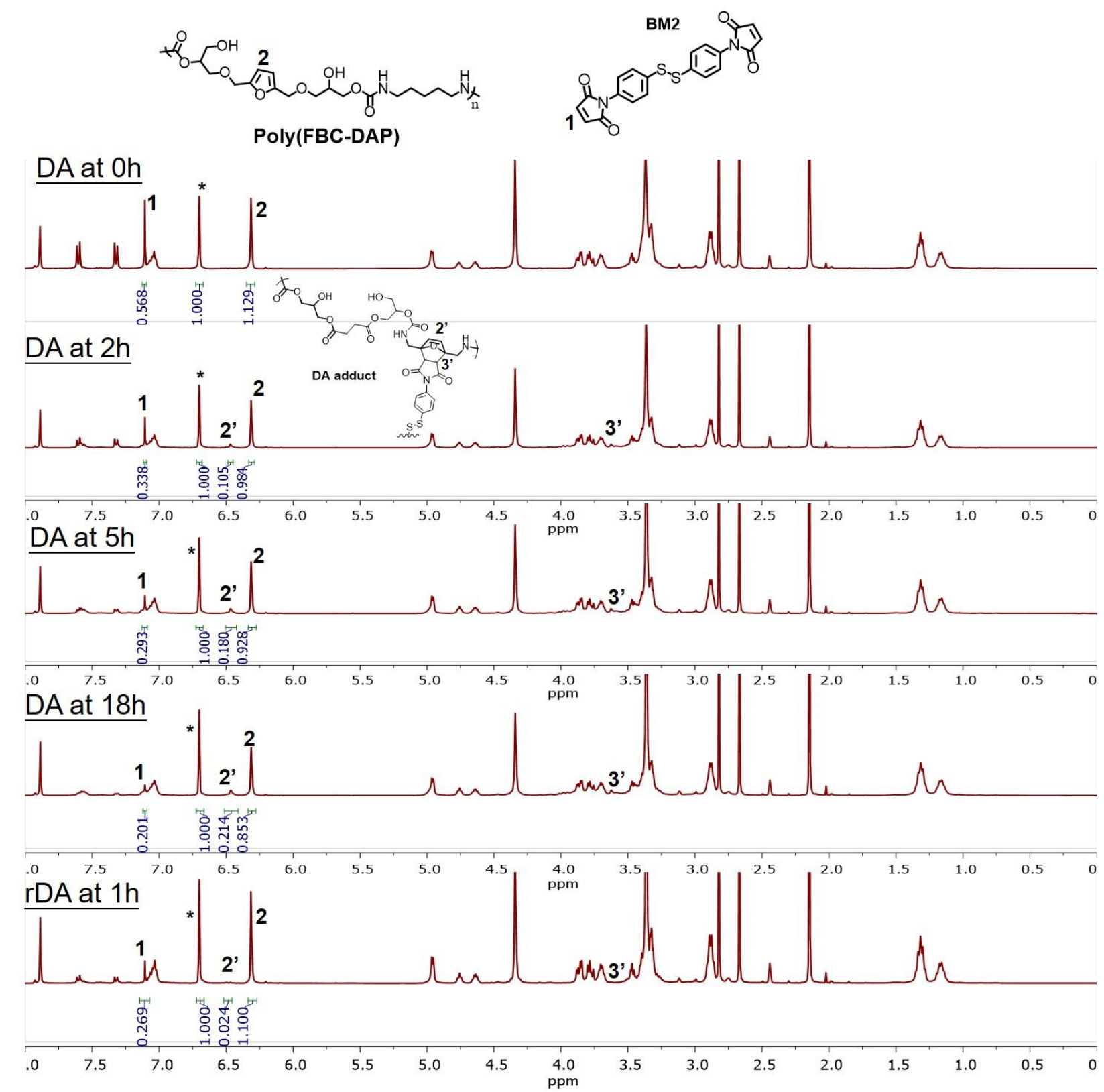

Figure S15. ${ }^{1} \mathrm{H}$ NMR spectra of Poly(FBC-DAP) and BM2 (furan:maleimide = 1:0.5) solution in d6-dmso. The DA reaction was carried out at $50^{\circ} \mathrm{C}$ for 18 hours and rDA reaction was carried out at $110{ }^{\circ} \mathrm{C}$ for 1 hour. * denotes the mesitylene peak which was used as internal standard. 


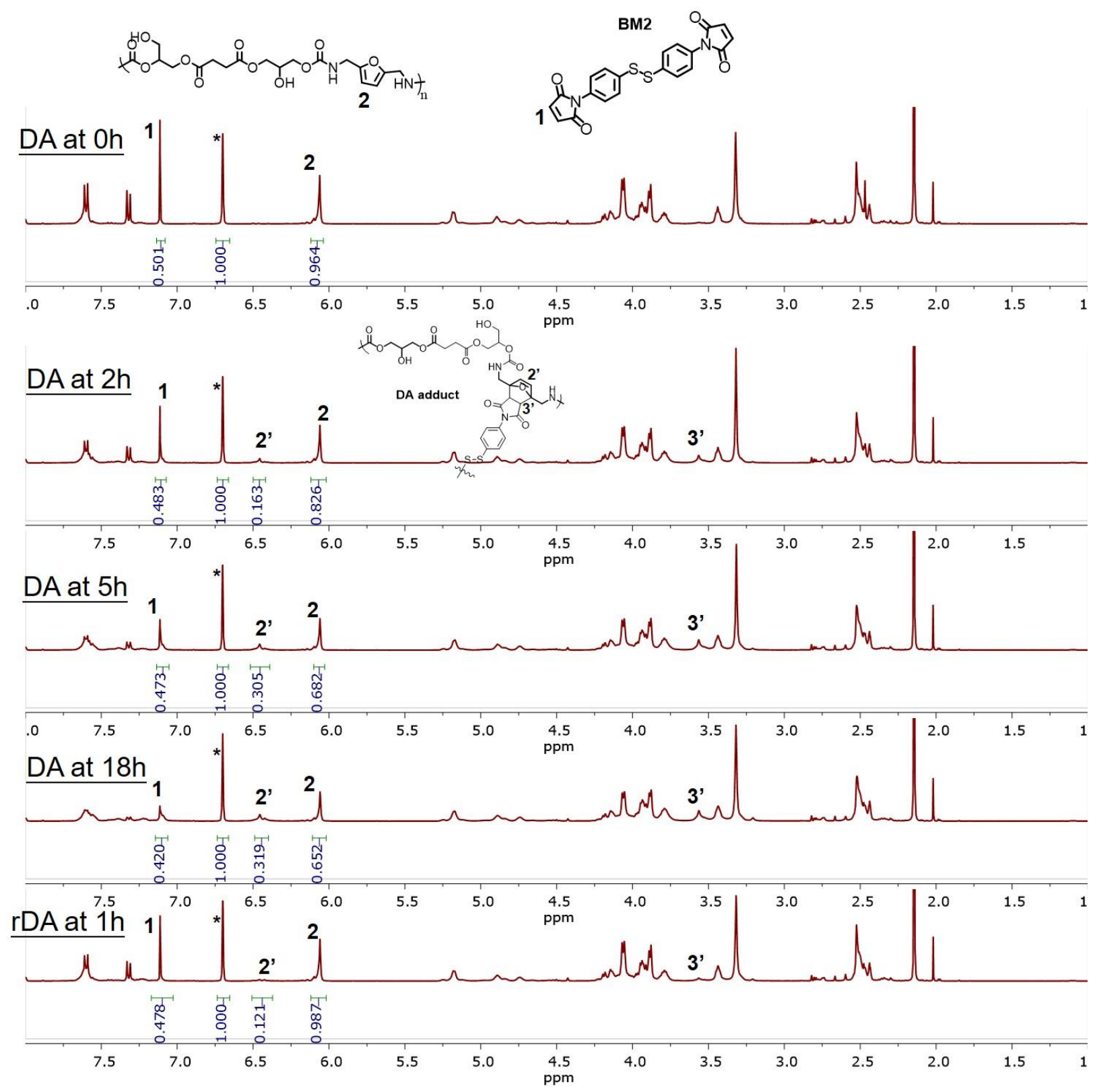

Figure S16. ${ }^{1} \mathrm{H}$ NMR spectra of Poly(SuBC-FBA) and BM2 (furan:maleimide = 1:0.5) solution in d6-dmso. The DA reaction was carried out at $50^{\circ} \mathrm{C}$ for 18 hours and $\mathrm{rDA}$ reaction was carried out at $110^{\circ} \mathrm{C}$ for 1 hour. * denotes the mesitylene peak which was used as internal standard. 
X. Microscopic images on thermo-healing and self-healing of crosslinked NIPU coatings

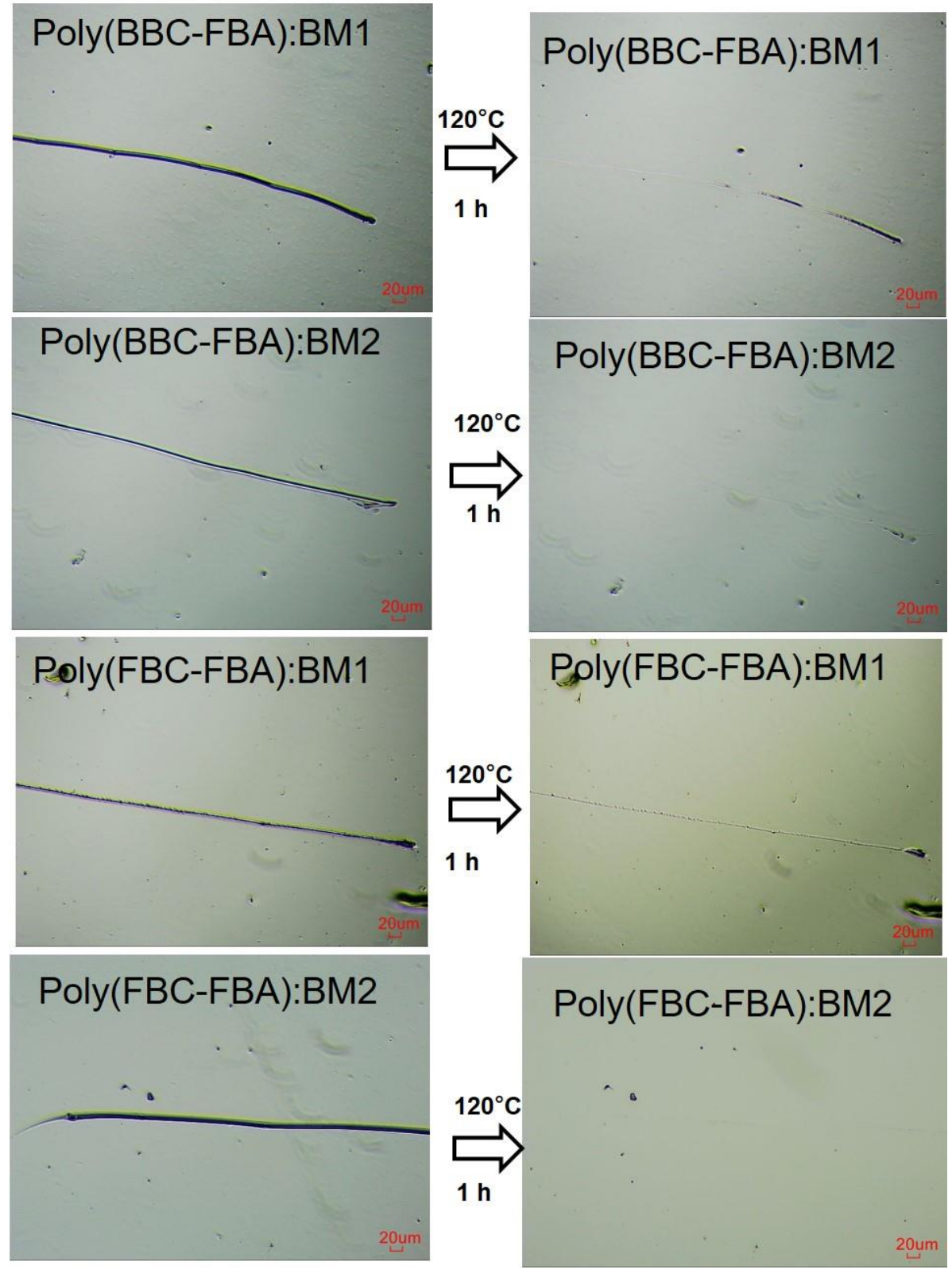

Figure S17. Microscopic images on thermo-healing of scratched poly(BBC-FBA) and poly(FBC-FBA) coating films (crosslinked with BM1 or BM2) on glass substrates at $120{ }^{\circ} \mathrm{C}$ for 1 hour. 


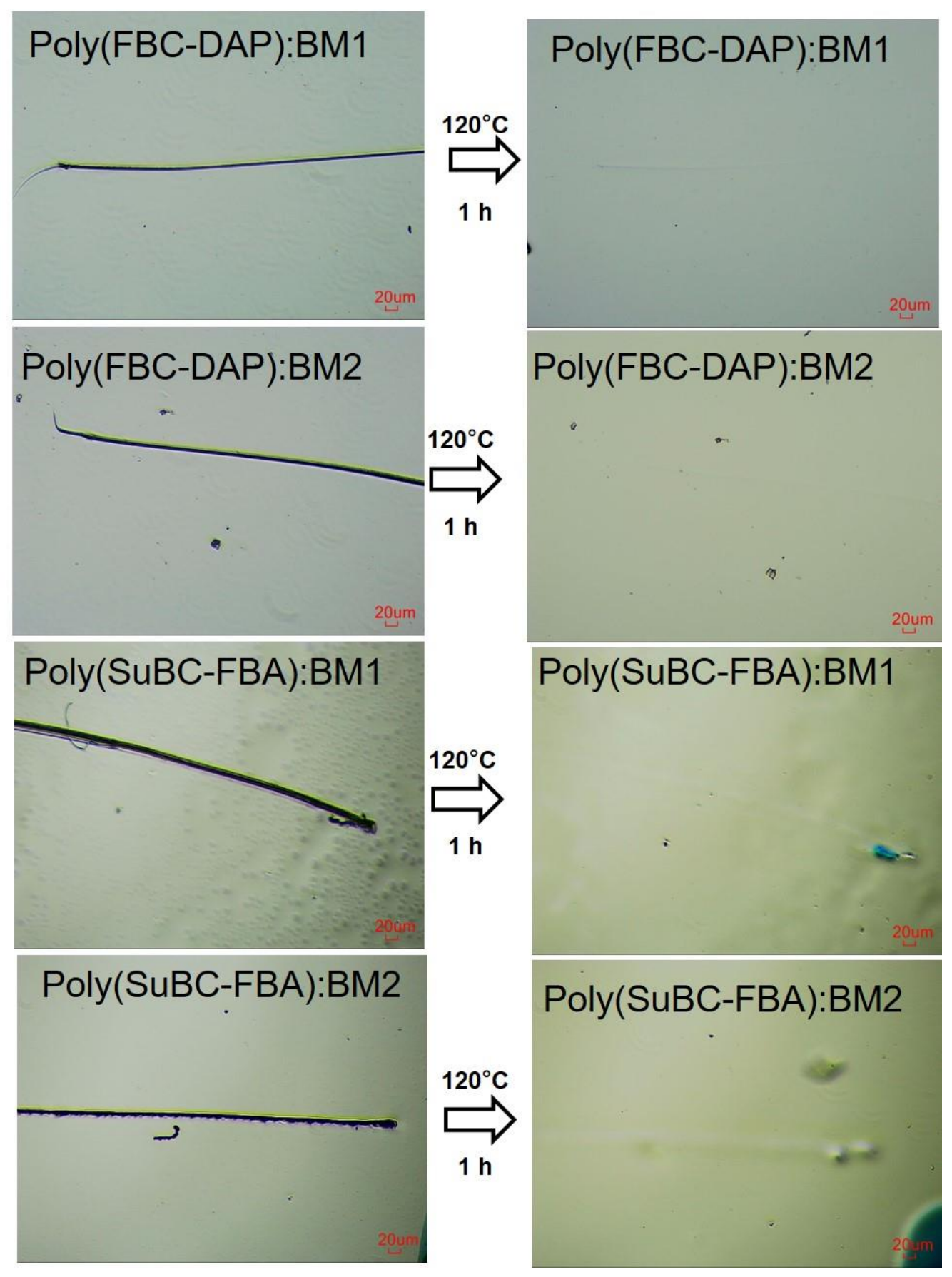

Figure S18. Microscopic (dark field) images on thermo-healing of scratched Poly(FBC-DAP) and Poly(SuBC-FBA) dry coating films (crosslinked with BM1 or $\mathrm{BM} 2)$ on glass substrates at $120^{\circ} \mathrm{C}$ for 1 hour. 


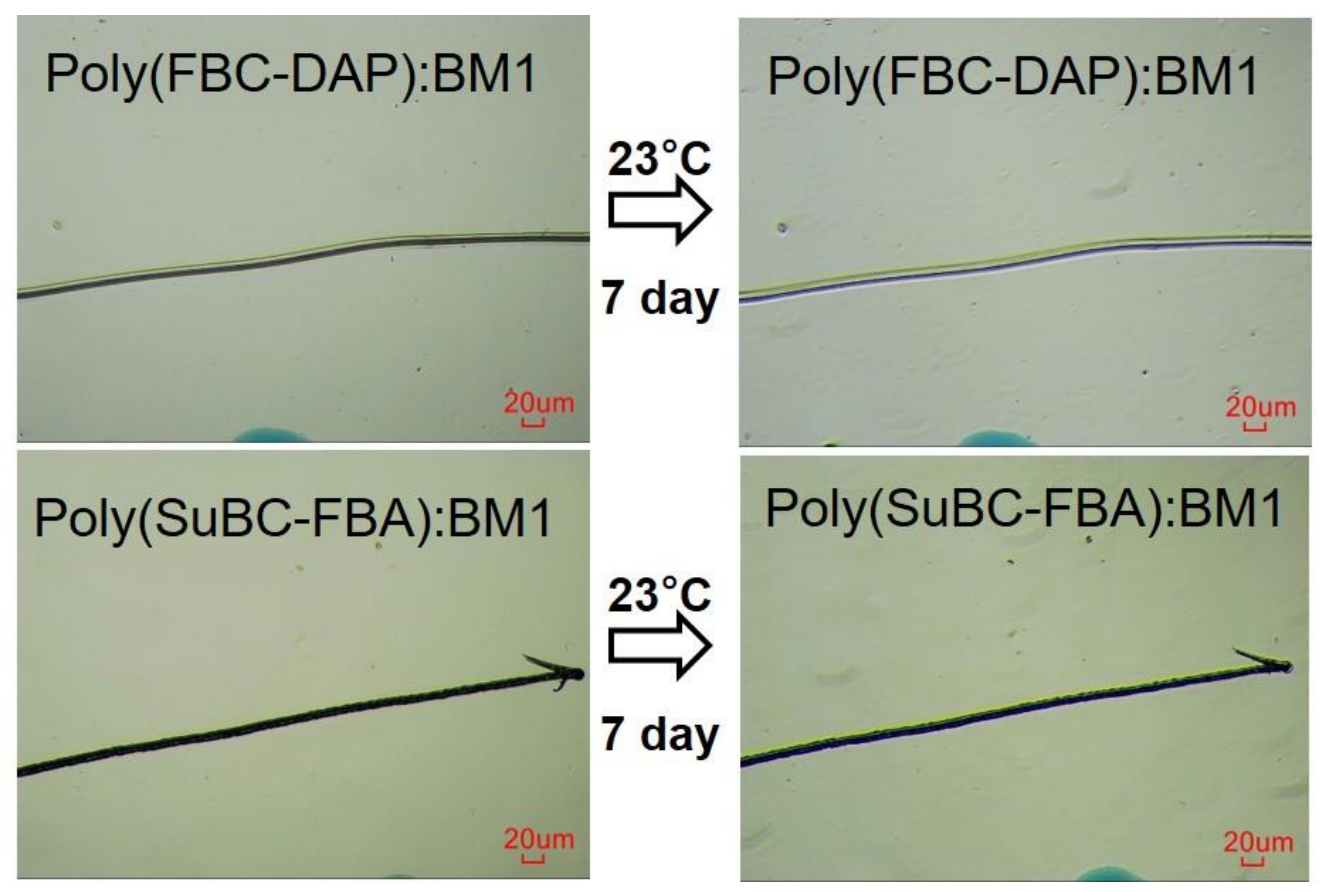

Figure S19. Microscopic images on healing of scratched Poly(FBC-DAP) and Poly(SuBC-FBA) coating crosslinked with BM1 on glass substrates before and after 7 days at $23{ }^{\circ} \mathrm{C}$ under dry argon atmosphere. The scattered black dots are deliberately placed for easy tracking of healing scratched sites. 


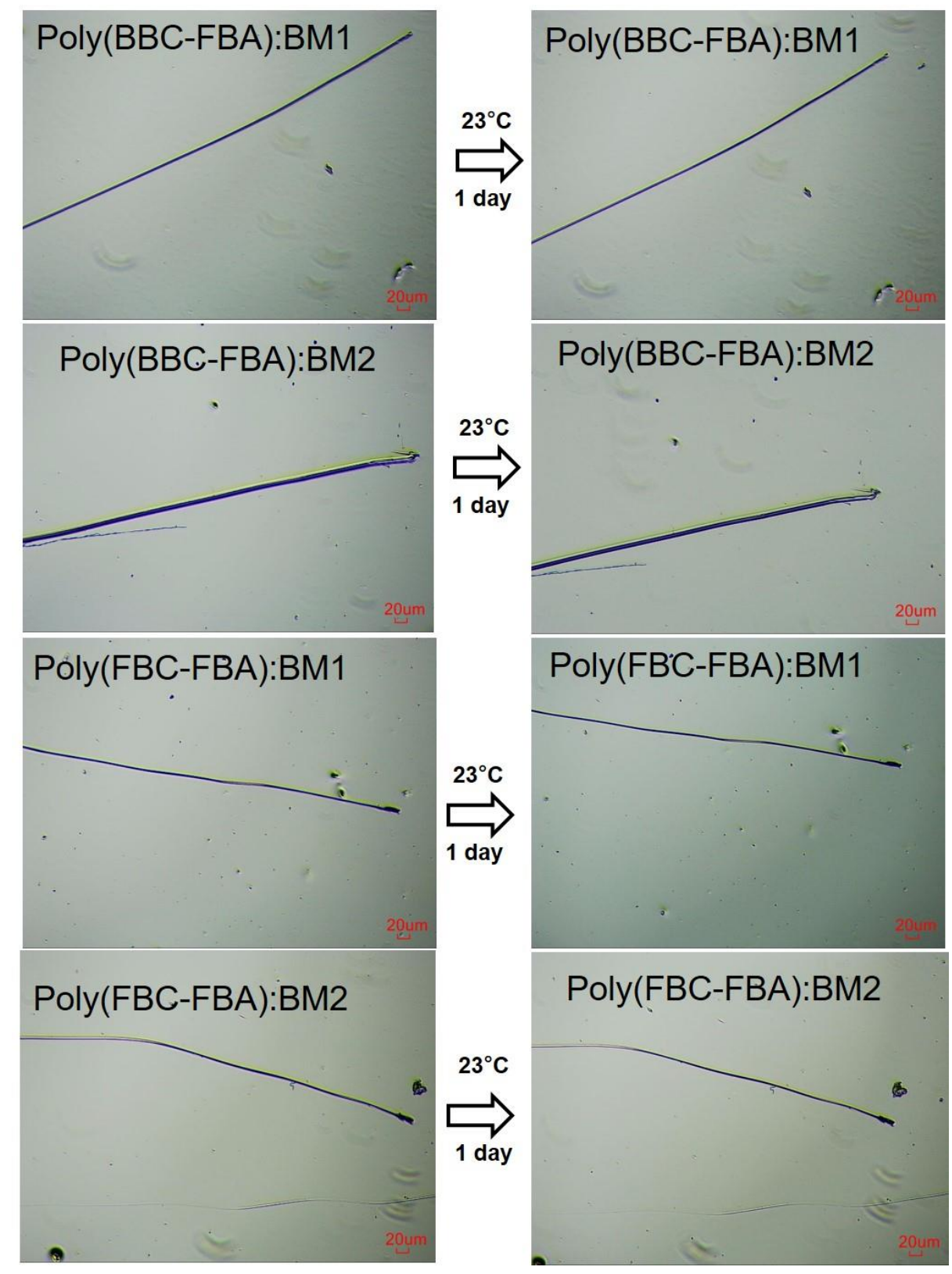

Figure S20. Microscopic images on self-healing test of scratched Poly(BBC-FBA) and Poly(FBC-FBA) coating films (crosslinked with BM1 or BM2) on glass substrates at $23^{\circ} \mathrm{C}$. All coating films were exposed to moisture in the atmosphere with a relative humidity of $70-90 \%$ for 2 days prior to scratch tests. 


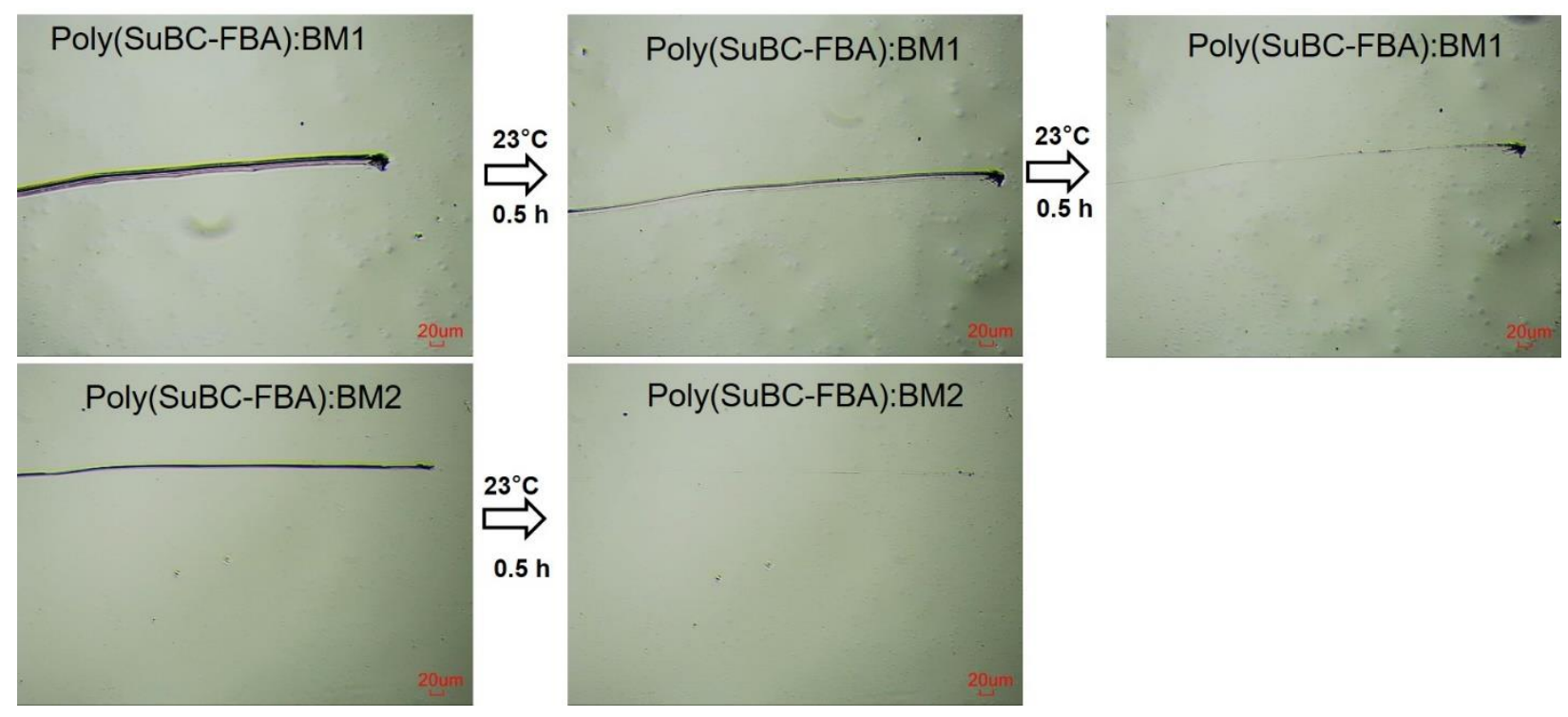

Figure S21. Microscopic images on self-healing test of scratched Poly(SuBC-FBA) coating films (crosslinked with BM1 or BM2) on glass substrates at $23{ }^{\circ} \mathrm{C}$. All coating films were exposed to moisture in the atmosphere with a relative humidity of $70-90 \%$ for 2 days prior to scratch tests. 

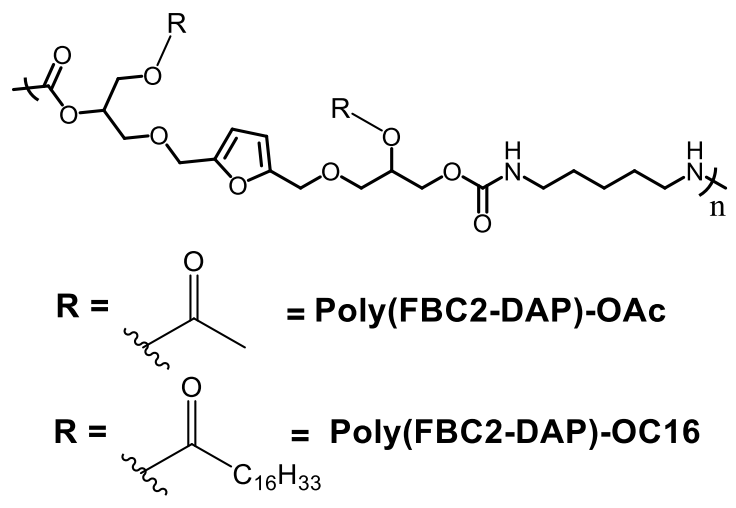

(a)
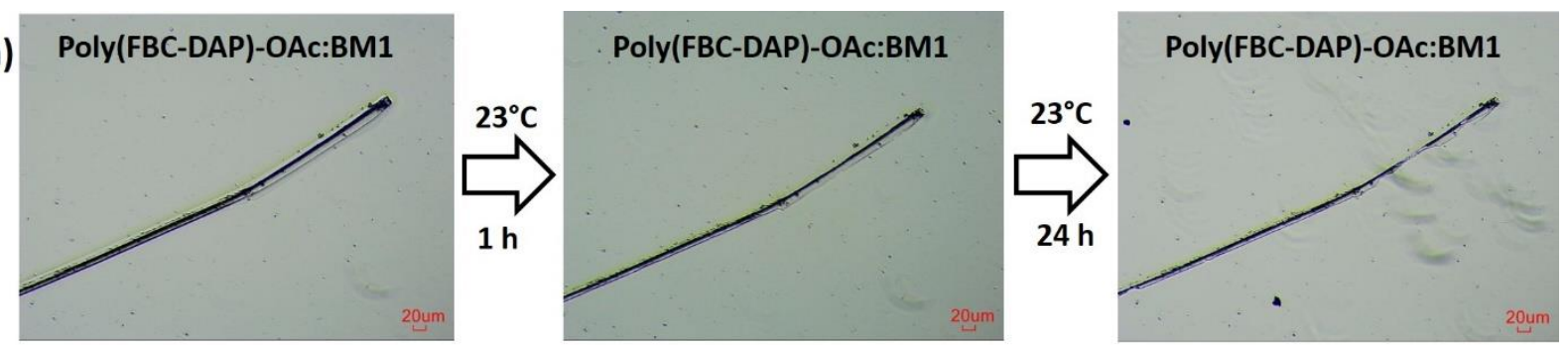

(b)
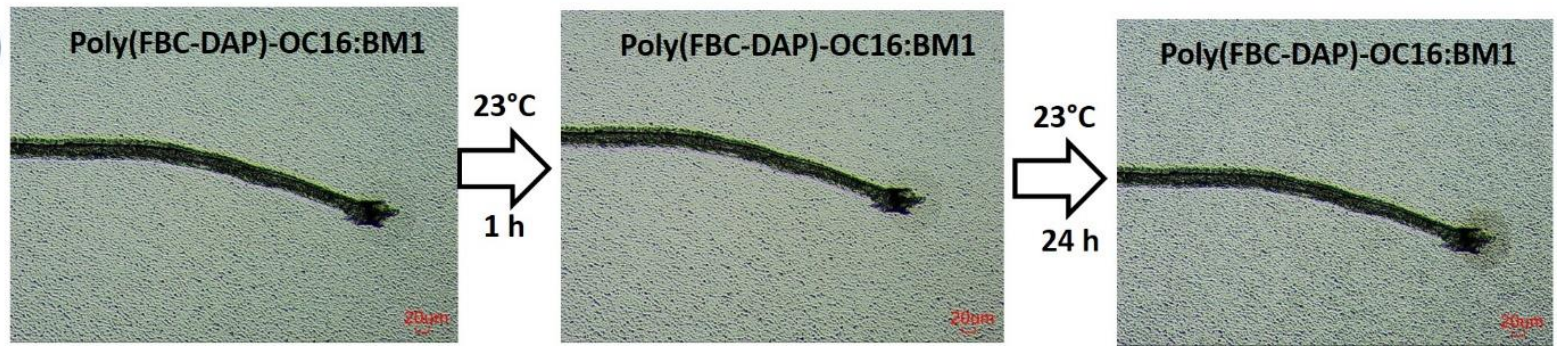

Figure S22. Microscopic images on self-healing test of scratched (a) poly(FBC$\mathrm{DAP})-\mathrm{OAc}$ and (b) poly(FBC-DAP)-OC16 coating films crosslinked with BM1 on glass substrates at $23{ }^{\circ} \mathrm{C}$. All coating films were exposed to moisture in the atmosphere with a relative humidity of $70-90 \%$ for 2 days prior to scratch tests. 


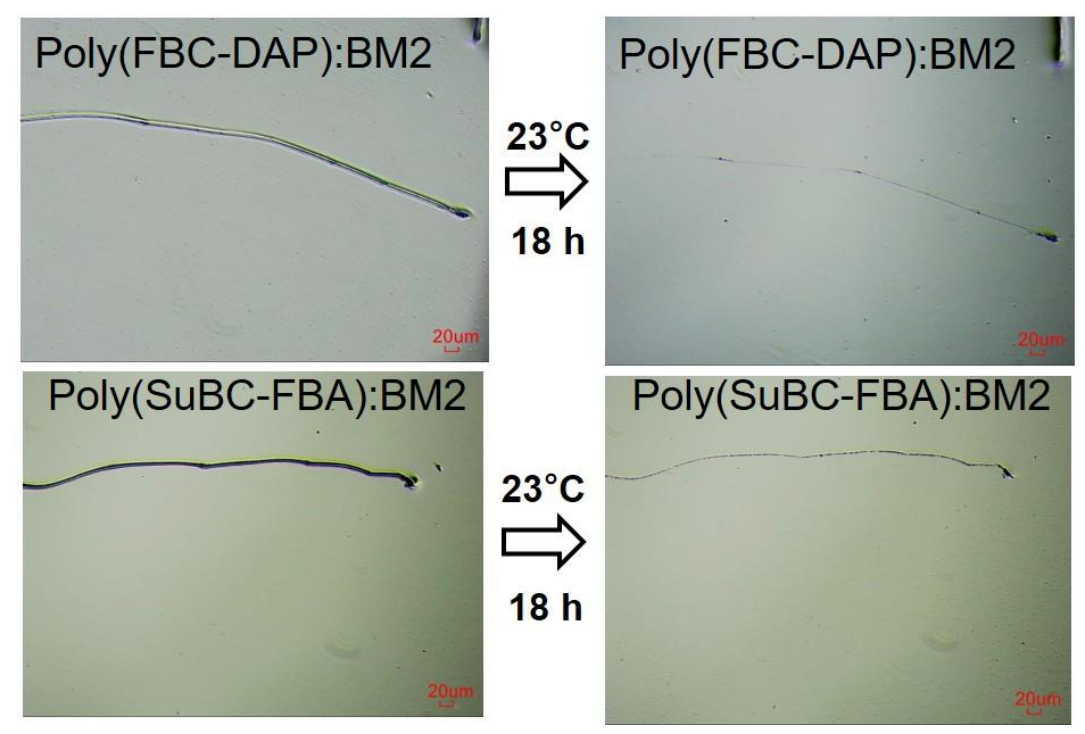

Figure S23. Microscopic images of self-healing of scratched crosslinked coating films produced from a) poly(FBC-DAP) \& BM2 and b) poly(SuBC-FBA) \& BM2 at room temperature and in dry conditions ( $\mathrm{RH}$ of $<24 \%$ ). 
XI. DSC plots of dry and moistened (poly(FBC-DAP)+BM2) coatings film

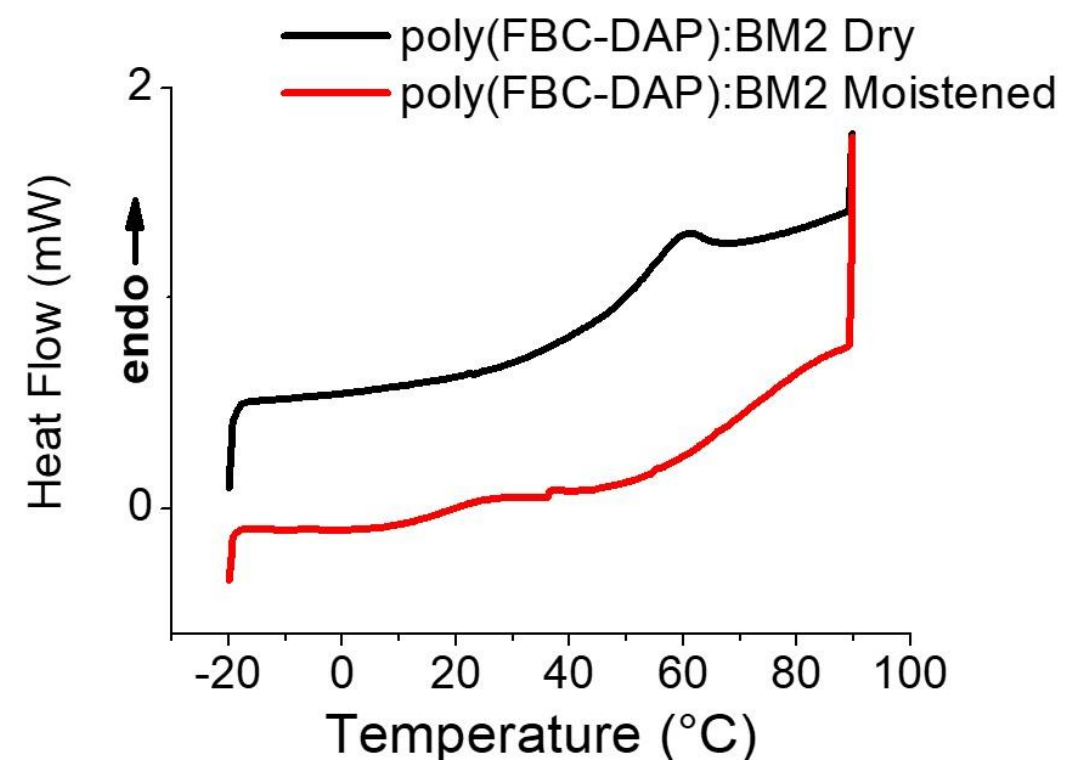

Figure S24. DSC plot for crosslinked (poly(FBC-DAP)+BM2) coatings film after drying under vacuum for 48 hours (black line), and exposure to moisture $(\mathrm{RH}>95 \%)$ for 48 hours (red line) at room temperature. 
XII. Table S2: Summary of mechanical properties of NIPU-bismaleimide coatings.

\begin{tabular}{|c|c|c|c|c|c|c|c|}
\hline NIPU & Bismaleimide $^{a}$ & $\begin{array}{c}\text { Film } \\
\text { thickness }^{b} \\
(\mu \mathrm{m})\end{array}$ & $\begin{array}{c}\text { Pencil } \\
\text { hardness }^{c} \\
\text { (Dry) }\end{array}$ & $\begin{array}{c}\text { Pencil } \\
\text { hardness }^{c} \\
\text { (moistened) }\end{array}$ & $\begin{array}{l}\text { Pendulum } \\
\text { hardness }^{d} \\
\text { (Dry) }\end{array}$ & $\begin{array}{l}\text { Pendulum } \\
\text { Hardness }^{\mathrm{d}} \\
\text { (moistened) }\end{array}$ & $\begin{array}{l}\text { Adhesion pull- } \\
\text { off strength } \\
\text { (MPa) }\end{array}$ \\
\hline \multirow[t]{2}{*}{ Poly(BBC-FBA) } & BM1 & $31.8 \pm 0.5$ & $\mathrm{HB}$ & $\mathrm{HB}$ & $179 \pm 6 s$ & $183 \pm 5 s$ & $5.85 \pm 0.05$ \\
\hline & BM2 & $31.7 \pm 1.0$ & $\mathrm{HB}$ & $\mathrm{HB}$ & $181 \pm 4 s$ & $178 \pm 2 s$ & $5.70 \pm 0.07$ \\
\hline \multirow[t]{2}{*}{ Poly(FBC-FBA) } & BM1 & $31.5 \pm 3.1$ & $\mathrm{~B}$ & $2 \mathrm{~B}$ & $166 \pm 7 \mathrm{~s}$ & $150 \pm 8 \mathrm{~s}$ & $5.77 \pm 0.01$ \\
\hline & BM2 & $31.9 \pm 4.2$ & $B$ & $2 B$ & $160 \pm 9 \mathrm{~s}$ & $147 \pm 8 s$ & $5.88 \pm 0.02$ \\
\hline \multirow[t]{2}{*}{ Poly(FBC-DAP) } & BM1 & $26.1 \pm 1.0$ & $2 B$ & $3 B$ & $105 \pm 3 s$ & $76 \pm 4 s$ & $5.90 \pm 0.03$ \\
\hline & BM2 & $29.7 \pm 1.1$ & $2 B$ & $3 B$ & $100 \pm 6 s$ & $79 \pm 4 s$ & $5.93 \pm 0.02$ \\
\hline \multirow[t]{2}{*}{ Poly(SuBC-FBA) } & BM1 & $31.1 \pm 2.8$ & $2 \mathrm{~B}$ & $3 B$ & $109 \pm 13 \mathrm{~s}$ & $91 \pm 5 s$ & $6.00 \pm 0.05$ \\
\hline & BM2 & $27.7 \pm 0.5$ & $2 B$ & $3 B$ & $108 \pm 9 s$ & $84 \pm 6 s$ & $6.11 \pm 0.06$ \\
\hline
\end{tabular}




\section{References}

[1] J. F. G. A. Jansen, A. A. Dias, M. Dorschu, B. Coussens, Macromolecules 2003, 36, 3861-3873.

[2] J. Seayad, S. Jana, A. M. Seayad, WO 2019190409 A1 2019.

[3] R. Jaratrotkamjorn, A. Nourry, P. Pasetto, E. Choppé, W. Panwiriyarat, V. Tanrattanakul, J. -F. Pilard, Journal of Applied Polymer Science 2017, 134, 45427.

[4] L. Milanesi, G. D. Reid, G. S. Beddard, C. A. Hunter, J. P. Waltho, Chemistry - A European Journal 2004, 10, 1705-1710.

[5] A. Cornille, C. Guillet, S. Benyahya, C. Negrell, B. Boutevin, S. Caillol, Eur. Polym. J. 2016, 84, 873888. 